Document downloaded from:

http://hdl.handle.net/10251/121367

This paper must be cited as:

García Sanjuan, F.; El Jurdi, S.; Jaén Martínez, FJ.; Nácher-Soler, VE. (2018). Evaluating a tactile and a tangible multi-tablet gamified quiz system for collaborative learning in primary education. Computers \& Education. 123:65-84. https://doi.org/10.1016/j.compedu.2018.04.011

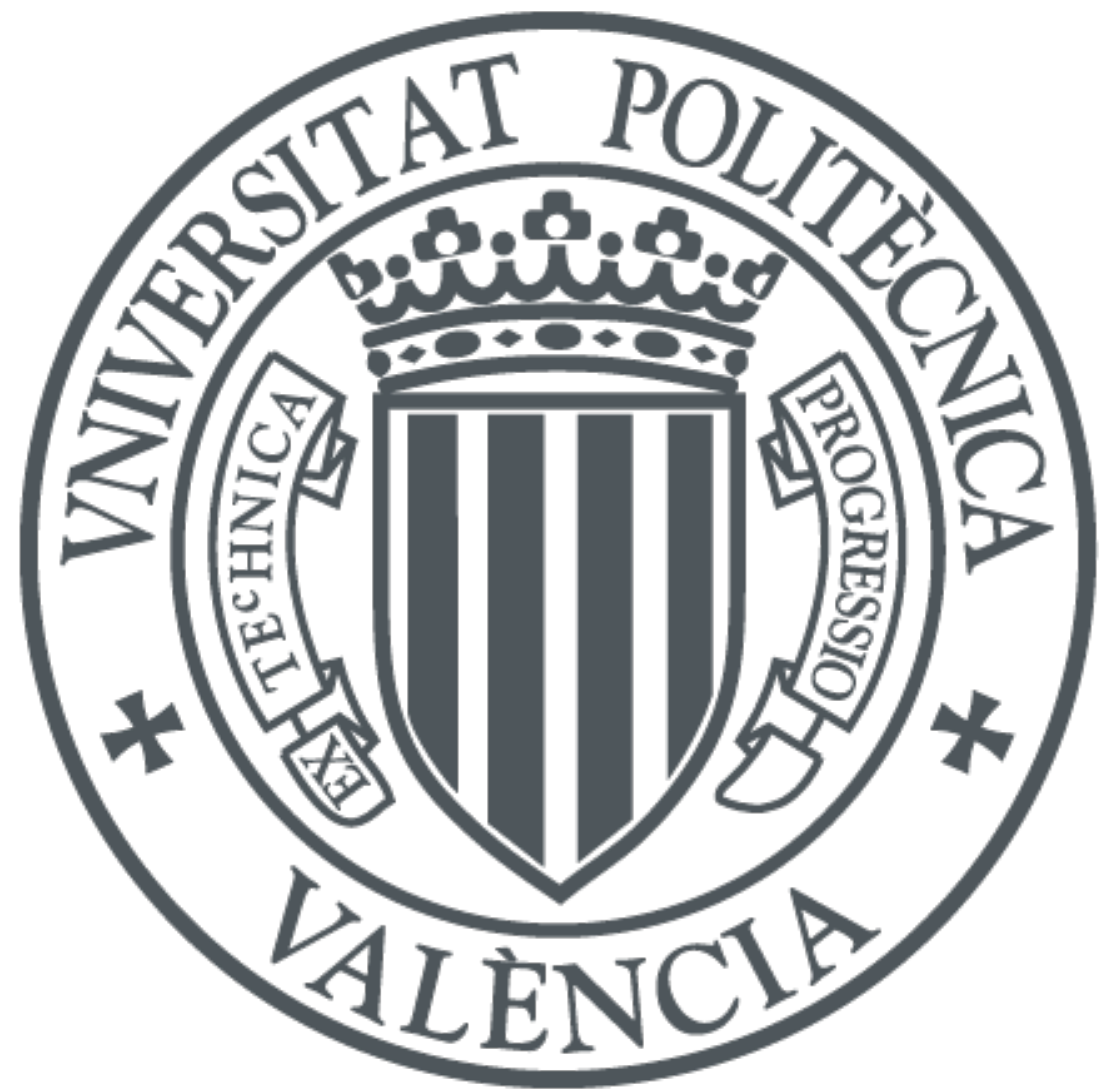

The final publication is available at

http://doi.org/10.1016/j.compedu.2018.04.011

Copyright Elsevier

Additional Information 


\title{
Evaluating a Tactile and a Tangible Multi-Tablet Gamified Quiz System for Collaborative Learning in Primary Education
}

\author{
Fernando Garcia-Sanjuan, Sandra Jurdi, Javier Jaen, Vicente Nacher
}

\begin{abstract}
Gamification has been identified as an interesting technique to foster collaboration in educational contexts. However, there are not many approaches that tackle this in primary school learning environments. The most popular technologies in the classroom are still traditional video consoles and desktop computers, which complicate the design of collaborative activities since they are essentially mono-user. The recent popularization of handheld devices such as tablets and smartphones has made it possible to build affordable, scalable, and improvised collaborative gamified activities by creating a multi-tablet environment. In this paper we present Quizbot, a collaborative gamified quiz application to practice different subjects, which can be defined by educators beforehand. Two versions of the system are implemented: a tactile for tablets laid on a table, in which all the elements are digital; and a tangible in which the tablets are scattered on the floor and the components are both digital and physical objects. Both versions of Quizbot are evaluated and compared in a study with eighty primary-schooled children in terms of user experience and quality of collaboration supported. Results indicate that both versions of Quizbot are essentially equally fun and easy to use, and can effectively support collaboration, with the tangible version outperforming the other one with respect to make the children reach consensus after a discussion, split and parallelize work, and treat each other with more respect, but also presenting a poorer time management.
\end{abstract}

\section{Keywords}

Computer-Supported Collaborative Learning (CSCL); Tangible User Interfaces (TUI); Multi-Display Environments (MDE); Tablets; Children

\section{Introduction}

Collaboration in the classroom has become a very popular research topic since it presents a plethora of benefits for learning. Johnson and Johnson (Johnson \& Johnson, 1989) and Panitz (Panitz, 1999) report on more than fifty social, psychological, and academic benefits, according to the classification by Laal and Ghodsi (Laal \& Ghodsi, 2012). Indeed, collaboration has been identified by many as a key $21^{\text {st }}$ century skill (Laal, Laal, \& Kermanshahi, 2012; OECD, 2005) that is being included in most current educational models (Hager et al., 2012; Wagner, 2008). There are many techniques to foster collaboration among students, one of them being through the gamification of learning activities (Kapp, 2012). Gamification is defined by Deterding et al. (Deterding, Dixon, Khaled, \& Nacke, 2011) as "the use of design elements characteristic for games in non-game contexts." It is an interesting and engaging approach, especially as traditional instructional approaches are now losing their popularity among students (Cheong, Cheong, \& Filippou, 2013b; Kapp, 2012). Nevertheless, as concluded by de Sousa Borges et al. (de Sousa Borges, Durelli, Reis, \& Isotani, 2014), there are not many approaches that combine gamification and computer-supported collaborative learning, and even fewer evaluations.

As previous studies reveal (Boyle et al., 2016; Connolly, Boyle, MacArthur, Hainey, \& Boyle, 2012; Hainey, Connolly, Boyle, Wilson, \& Razak, 2016), the most popular technologies in game-based learning are still traditional video consoles and desktop/laptop computers. These platforms, however, present several drawbacks that make them suboptimal for children, e.g., they are not very intuitive; they require users to stay in a single location, thus preventing them from moving around and exercising; and they are essentially mono-user, which complicates the design of activities to foster social abilities and collaboration (Nacher, Garcia-Sanjuan, \& Jaen, 2016b). 
Devices such as smartphones or tablets are now very affordable and in common use. Since they are small and mobile, users are able to form improvised groups virtually anywhere. By following a "Bring Your Own Device" (Ballagas, Rohs, Sheridan, \& Borchers, 2004) scheme, it is possible to build Multi-Display Environments (MDE) to support co-located collaborative educational activities on a table-like setting by coordinating interaction across these devices. This presents several benefits in terms of workspace awareness and facilitating the coordination of the activity (Gutwin \& Greenberg, 1998, 2002), and also of increasing the parallelism and fluidity of the interaction (Hornecker, Marshall, Dalton, \& Rogers, 2008; Rick, Marshall, \& Yuill, 2011). In addition, if the devices are scattered over a large area, physical activity can be encouraged, which is a key factor in children's development (Tomporowski, Lambourne, \& Okumura, 2011) and is beneficial for supporting the construction of a positive social space for collaborative learning (Malinverni \& Burguès, 2015). This would avoid the problems identified by Seitinger (Seitinger, 2006), who points out that this type of device does not encourage full-body motion.

How to interact with these multi-tablet environments is therefore a critical issue. Mobile devices are designed to be interacted mainly via touch, which has been proven very straightforward even for the youngest children (Nacher, Jaen, Navarro, Catala, \& González, 2015), however, tactile interaction on current handheld devices is usually limited to the small area of the displays, which can lead to the occlusion of the screen and the underuse of the peripheral space. In contrast, Tangible User Interfaces (TUI) offer interaction through the manipulation of physical objects, which present an added value in childhood education "as they resonate with traditional learning manipulatives" (Strawhacker \& Bers, 2014) and enable the exploration of the physical world, which "facilitates both the acquisition of information about, and experience with, the environment, together with exploration of different combinations of information" (Price, Rogers, Scaife, Stanton, \& Neale, 2003). Despite these advantages, according to a review by Garcia-Sanjuan et al. (Garcia-Sanjuan, Jaen, \& Nacher, 2016b) there are not many studies that make use of tangible interactions in tablet-based MDEs.

In our opinion, future learning environments that target collaborative learning must support negotiation, planning, communication, and organization. This work is a first step towards understanding how MDEs based on tactile versus tangible interaction can effectively support the development of these skills among primary school children. In this respect, the contributions of this paper are manifold: Firstly, it proposes a multi-display gamified quiz system using handheld tablets to be used for collaborative learning. The activity supports different types of questions, which can be defined by teachers beforehand. To enforce collaboration, the students must negotiate and plan the actions to be taken in order to conjointly drive a robot to the correct answers. Secondly, two versions of the system are presented, which differ on workspace size and interaction modalities-touch and tangible. Both interaction mechanisms are meant to be generic and therefore decoupled from the educational contents displayed on screen. Thirdly, both versions are compared in terms of the quality of the collaboration they support through a study conducted with eighty primary school children. Finally, the user experience of the children with both platforms is reported.

\section{Background}

\subsection{Gamification for Collaborative Learning}

According to Dominguez et al. (Domínguez et al., 2013), the most common goal of gamification is to increase user experience and engagement. This can influence student motivation and in turn result in better quality learning (Deci \& Ryan, 1990; Eales, Hall, \& Bannon, 2002). From the analysis of the literature, Kocadere and Çağlar (Kocadere \& Çağlar, 2015) identify other benefits of gamification in learning contexts, such as being able to create an enjoyable learning environment, ensuring active participation, and increasing achievement-also identified by Dominguez et al. (Domínguez et al., 2013). However, gamification should be applied with caution because, as Robertson points out (Robertson, 2010), many approaches tend to reduce gamification to mere "pointification" (i.e., assigning points and badges), since it is "the least essential to games." A study by Kyewski and Krämer (Kyewski \& Krämer, 2018) suggests that assigning badges might not have an impact on either motivation, activity, or performance, and Hanus and Fox (Hanus \& Fox, 2015) did find negative effects of pointification on motivation, satisfaction, empowerment, and performance. In this line, Cheong et al. (Cheong et al., $2013 \mathrm{~b}$ ) argue that gamification should go beyond adding individual game elements mechanically: it should be about the integration of these elements to provide a motivating and meaningful experience.

Gamification can be particularly useful in learning environments to promote collaboration (Kapp, 2012). Li et al. (C. Li, Dong, Untch, \& Chasteen, 2013) applied it to an online collaborative learning 
environment for computer science students by introducing participation points, levels, and leaderboards. Their goal was to motivate students to help each other to solve and improve programming problems, and reported good initial acceptance of the platform among the students. Similarly, Simões et al. (Simões, Redondo, \& Vilas, 2013) proposed a gamified web-based social learning environment for children aged 6-12, their parents, and teachers, in which they used elements such as rewards and immediate feedback, but they did not conduct an evaluation. Betts et al. (Betts, Bal, \& Betts, 2013) introduced experience points and levels in a web-based collaborative learning tool, and observed a positive correlation between assignment scores and the number of experience points earned, as well as between the overall scores and the degree of participation. De-Marcos et al. (de-Marcos, Garcia-Lopez, \& Garcia-Cabot, 2016) compared an educational game and social networking versus gamification and social gamification (a combination of a gamified activity making use of social networks), and found that the latter outperformed the rest in terms of learning performance as well as the immediacy of achieving said performance.

De Sousa Borges et al. (de Sousa Borges et al., 2014) conducted a systematic mapping of the literature on gamification and learning, and extracted three main conclusions that also apply to the aforementioned works: Firstly, gamification is usually studied in the context of higher education, and children in primary school are the ones that receive the least attention in this respect. Secondly, user studies tend to focus on engagement and disregard other aspects of user experience. And, thirdly, there are not many works that combine gamification and Computer-Supported Collaborative Learning. From our own perspective, we would also add that the existing research works that do combine these two topics usually focus on remote collaboration and disregard co-location.

\subsection{Gamified Assessment for Learning}

The assessment of learning (e.g., through quizzes) is a well-known and popular mechanism to support learning. Quizzes are an effective learning strategy because they support retrieval practice, which is, as pointed out by Blunt and Karpicke (Blunt \& Karpicke, 2014), "a powerful way to enhance long-term meaningful learning of educationally relevant content." However, when used in examinations, especially high-stake ones, often cause anxiety among students and barely favor it (Amrein \& Berliner, 2002; Kocadere \& Çağlar, 2015). According to Stiggins and Chappuis (Stiggins \& Chappuis, 2001), assessment should be devised for learning as well, and gamification might be a mechanism to accomplish it (Kocadere \& Çağlar, 2015).

Tanaka et al. (Tanaka, Uwano, Ichinose, \& Takehara, 2016) introduced a leaderboard in a web-based quiz tool, and observed increased motivation among the students for exam preparation. Similar solutions were proposed by Şahin et al. (Şahin et al., 2017) and by Cheong et al. (Cheong, Cheong, \& Filippou, 2013a; Cheong et al., 2013b), who found applying gamification principles such as points, feedback, and leaderboards to quizzes increased both motivation, enjoyment, and fun. With collaboration in mind, Moccozet et al. (Moccozet, Tardy, Opprecht, \& Leonard, 2013) gamified a group work activity to assess the level of participation of each student and encourage participation by rewarding points to each contributor and displaying them on a leaderboard. Another interesting approach is by Kocadere and Çağlar (Kocadere \& Çağlar, 2015), who applied some of the gamification elements by Werbach and Hunter (Werbach \& Hunter, 2012) to a quiz using a board-shaped interface, i.e., avatars, levels, content unlocking, leaderboard, achievements, virtual goods, points, teams, and badges; and found that, not only it did not cause exam anxiety, but elicited enjoyment, motivation, flow, and learning. Using a board interface is particularly interesting to promote collaboration. As pointed out by Harris (Harris, 2009), in quiz-style board games students "participate and collaborate as members of a social and intellectual network of learners and ... the learning takes place as a natural and authentic part of playing these board games." This is also confirmed by Westergaard (Westergaard, 2009) who points out that quiz-style games "can encourage participation and foster an informal, positive and energetic learning environment." None of these works, however, consider co-located activities, which, as explained above, could have benefits for collaborative learning. As counterexamples, Kahoot ${ }^{1}$ is a popular learning platform to answer gamified quizzes in a co-located collaborative or competitive way, which has been shown to improve learning performance and increase motivation (Tsihouridis, Vavougios, \& Ioannidis, 2017; Wichadee \& Pattanapichet, 2018) and is well accepted by teachers (Batsila \& Tsihouridis, 2017). SecretSLQ (FitzWalter, Tjondronegoro, Koh, \& Zrobok, 2012), on the other hand, is a gamified quiz system for children based on mobile devices and interaction with physical objects to learn about the purpose and functioning of a library. It makes use of four main game elements, a scavenger hunt, challenges, points, and a leaderboard. The participants generally enjoyed the activity and were comfortable using the devices.

\footnotetext{
${ }^{1}$ https://kahoot.com/
} 
However, the authors report on several issues that suggest a need for further studies on interaction modalities with mobile devices to increase the quality of experience.

\subsection{Interaction Modalities for Collaborative Learning}

\subsubsection{Tactile Mobile Devices}

The recent popularization of smartphones and tablets has given rise to more natural interactions thanks to multi-touch technology and embedded sensors such as camera and GPS. Tactile interactions have been proven very straightforward even for the youngest children (Nacher, Jaen, Catala, Navarro, \& Gonzalez, 2014; Nacher et al., 2015). According to Shneiderman et al. (Shneiderman, Plaisant, Cohen, \& Jacobs, 2009), direct touch enables natural interactions for three reasons: a) the visibility of objects and actions of interest; b) the replacement of typed commands by pointing actions on the objects of interest; and c) the rapid, reversible, and incremental actions which help children to keep engaged and give them control over the technology avoiding complex instructions that complicate the interaction. Additionally, these devices' size and shape stimulate physical mobility, which has been shown to provide high motivation (Sun, 2012) as well as social, academic, and health benefits (Staiano \& Calvert, 2011). However, when collaboration is to be fostered in learning environments, it is often done in detriment of physical mobility, by seating students together around the display. Mitgutsch et al. (Mitgutsch, Schirra, \& Verrilli, 2013) designed an app to introduce youngsters to communication difficulties in a workplace. Two students seated in front of each other with their own tablets had to communicate to achieve a higher common objective. Since the devices were considered private instruments, each user was only able to see the results of the other's actions on their own screen and then engage in a conversation, but they were not fully aware of what the other was doing. A more interesting solution would be, as identified by Falloon and Khoo (Falloon \& Khoo, 2014), to have a multi-tablet setting in which the devices were placed on a table publicly available, which would increase workspace awareness and, in turn, collaborative performance (Hornecker et al., 2008). In this respect, Proportion (Rick, 2012) is a collaborative app that places two children in front of a shared tablet to help them learn about proportions and ratios. They have good awareness of what the other participant is doing and they can communicate, but collaboration is not enforced since one user can monopolize all the interactions. However, since only one tablet is used, the workspace area is very limited.

\subsubsection{Tangible User Interfaces (TUI)}

Tactile interactions on the current mobile devices have the disadvantage of usually being limited to the small area of the displays, which can lead to the occlusion of the screen and the underuse of the peripheral space. As researchers like Soute et al. (Soute, Markopoulos, \& Magielse, 2010) showcase, making interaction transcend the boundaries of a display by having the children interact with tangible objects can enable fun experiences and stimulate social interaction and physical activity. Antle and Wise (Antle \& Wise, 2013) reveal that TUIs "may facilitate specific cognitive, constructivist, embodied, distributed social processes and mechanisms that are supportive of learning." Also, in the words of Marshall (Marshall, 2007), "tangible interfaces might be particularly suitable for collaborative learning. They can be designed to create a shared space for collaborative transactions and allow users to monitor each other's gaze to achieve interaction more easily than when interacting with a graphical representation on a display. They might also increase the visibility of other member's activity, better communicating the current state of their work and potentially encouraging situated learning." In this respect, Stanton et al. (Stanton et al., 2001) designed a TUI for collaborative storytelling. Multiple children were gathered around a big vertical screen that displayed the different drawings that composed a given story. They could then navigate through the drawings by walking on a "magic carpet" on the floor. This carpet had multiple pressure sensors underneath that triggered different operations when stepped on: pan left/right, and zoom in/out. If multiple sensors were pressed simultaneously, the operations would be summed, so the children would have to coordinate themselves to perform sensible actions. To move the drawing up and down, they possessed two physical props that had to be shown to a camera. By placing different barcodes in front of said camera, new drawings were displayed on the screen. The authors suggest that collaborative work can be encouraged by using big-sized TUIs and physical props, because the latter slow down the pace of interaction and increase the effort required to make manipulations, which entails more communication and discussion among the students. AGORAS (Catala, Garcia-Sanjuan, Pons, Jaen, \& Mocholi, 2012) is an educative platform to collaboratively create games. Although it is devised for tabletops, the users use tangible objects as containers of digital game components (e.g., entities and behaviors), which facilitates their manipulation, sharing, and reuse. This system is intended to foster creativity as well as to build games that teach concepts of geometry and physics. Chipman et al. (Chipman, Fails, Druin, \& Guha, 2011) opt for bringing tangible interactions to mobile devices. They present an app for young children to 
collaboratively learn about patterns using tablets and RFID-tagged objects. The children scan an object with the RFID reader attached to a tablet and then they paint on it with a certain color that identifies them. Later, when another child scans said object, they can draw on top of previous drawings, thereby making the painting collaborative. The activity allows the participants to be aware of what each child has made, and to communicate with one another to ask who is represented by a given color, however, the communication fostered here is quite naive, and even though the children collaborate to reach a common goal, they perform their tasks individually. These works focus on specific learning domains because the tangibles represent concepts of the domain itself, which is a popular approach in the educational use of TUI (Marshall, 2007). We propose instead to make the educational digital contents independent of the tangible mechanisms they are interacted with.

Robots can be examples of TUI if they can be interacted via direct touch and manipulation, hence benefiting from the advantages of tangible manipulation described above. Li et al. (L.-Y. Li, Chang, \& Chen, 2009) argue that robots "capture the imagination" of children, and Mubin et al. (Mubin, Stevens, Shahid, Mahmud, \& Dong, 2013) that they provide both the ability to add social interaction to the learning context and a tangible and physical representation of learning outcomes. According to Mubin et al. (Mubin et al., 2013), there is a trend of using robots in education under the theory of constructionism (Papert, 1980), which consists of acquiring knowledge through building a physical artifact (in this case, a robot) and reflecting on one's problem solving experience based on the motivation to build it. A popular platform used in this context is Lego Mindstorms ${ }^{2}$, although the learning benefits of building robots with it are not yet clear enough (McNally, Goldweber, Fagin, \& Klassner, 2006), and they have certain drawbacks that could prevent their being adopted by schools. For example, Martin et al. (Martin, Butler, \& Gleason, 2000) introduced this platform in a primary school for a whole year and found that, even though they were able to build creative designs successfully, the teachers struggled with its learning curve. Our approach relies instead on a robot as a companion to motivate the children and thus facilitate the learning process.

\subsubsection{Comparison of Tactile and Tangible Interactions}

Aside from previous comparisons between digital and physical (traditional) interfaces (e.g., (Finkelstein et al., 2005; Gire et al., 2010; Zacharia \& Olympiou, 2011)), several previous studies have compared fully digital and tangible user interfaces in collaborative settings, however, they tend to focus on technical aspects or individual user experience rather than on how they can support collaborative learning. Xie, Antle, and Motamedi (Antle, 2013; Xie, Antle, \& Motamedi, 2008) compared three interfaces for solving jigsaw puzzles in pairs: one fully physical, another fully digital (running on a laptop and controlled by mouse), and a TUI, which enhanced the physical jigsaw pieces with digital video and audio feedback. Although no significant differences were observed for children's self-report of enjoyment among the three conditions, several differences were noted in favor of tangible interaction, such as reducing cognitive load (freeing up resources for skills development) and enhancing communication through sharing physical objects. Fails et al. (Fails et al., 2005) conducted a comparative study between a TUI and a desktop-based interface for collaborative learning to teach children about environmental health hazards and how to avoid them. Their study reveals some differences between the interfaces in favor of the tangible one. Not only the students expressed more interest in the TUI version and interacted more with it than with the desktop version, but they also needed less help from adults, constructed more elaborated responses, and expressed less times not knowing the answer.

Others have compared touch and tangible interfaces, showing that neither outperforms the other in all conditions. Schneider et al. (Schneider, Jermann, Zufferey, \& Dillenbourg, 2011) compare multi-touch and tangible interactions on a tabletop to build a warehouse by composing blocks. Their results indicate that the tangible interface, which relies on manipulating physical objects on the screen, presents better performance results as well as more exploration of alternative solutions, more playfulness, and more collaboration than the tactile interface. Moreover, they show that performance is strongly correlated to collaboration and playfulness in the touch condition, whereas it is strongly correlated to more exploration in the TUI. Other studies like (Catala, Garcia-Sanjuan, Jaen, \& Mocholi, 2012; Tuddenham, Kirk, \& Izadi, 2010) indicate that tangible interactions on top of a screen are more effective to support basic manipulations such as acquisitions, translations, and rotations. However, Catala et al. (Catala, GarciaSanjuan, Jaen, et al., 2012) show touch dragging as more effective for exploration of digital collections in certain widgets. As the analysis of these studies reveals, comparisons between tactile and tangible interfaces have been conducted mainly with tabletop devices, and not much work has been done in this

\footnotetext{
${ }^{2}$ https://www.lego.com/en-us/mindstorms
} 
respect with tablets. As a counterexample, Bock et al. (Bock, Fisker, Topp, \& Kraus, 2015) do conduct a comparison of touch and tangible interactions on a single tablet. The study evaluates the users' preference for one or the other interface, but no significant results are obtained. Regardless of the interactive platform, these works only consider tangible interactions on the digital screen. In this respect, JadanGuerrero et al. (Jadan-Guerrero, Jaen, Carpio, \& Guerrero, 2015) conduct a comparison between a touch and a tangible interface for tablets in which touch occurred on screen whereas tangible interactions take place around the device, thus preventing screen occlusion. The evaluation conducted focuses on the experience children with Down syndrome had with a literacy application, and results suggest tangible manipulations being easier as well as fostering more verbalizations. However, again, this study only considers collaborative teacher-student learning in the context of a single shared tablet.

In short, comparisons between tangible and touch interactions have usually focused on technical aspects and have been conducted for tabletops, with tangible interaction being performed on the screen itself. To our knowledge, no previous works have considered comparing these interaction modalities in terms of their implications for designing an activity with an MDE in which interaction spans across multiple devices and can happen outside the display. In this paper we study these implications for collaborative learning through a gamified quiz activity deployed on a multi-tablet setting in two modalities: one fully digital and tactile, and another tangible.

\section{Quizbot: A Multi-Tablet Gamified Quiz System for Collaborative Learning}

The four gamification dynamics identified by Werbach and Hunter (Werbach \& Hunter, 2012) were taken into consideration in designing our collaborative learning activity: constraints, relationships, progression, and emotions. These have also been used in the design of other gamified board-shaped quiz settings, such as the one proposed by Kocadere and Çağlar (Kocadere \& Çağlar, 2015). By taking into consideration the criticism of pointification described above, we decided to leave points, badges, and leaderboards out of our design, and instead focus on other components to support the aforementioned dynamics, as described below.

Quizbot was designed as a tablet-based MDE to foster collaboration by means of several general constraints that were considered during its design. First, the gamification dynamics would need the joint intervention of several students simultaneously so that no single child could make progress alone. Second, the quiz would require the team to explore and discuss the different choices of action to take in the pursuit of a goal by means of communication, planning, and negotiation. Finally, it would require the continuous coordination of actions during the course of the activity in real time to achieve the predefined goal. These constraints were also designed to promote a collaborative relationship between the students.

With respect to progression, a simple design was adopted that would force children to concentrate on the collaboration dimension rather than on understanding complex rules or procedures. Quizbot is, in essence, a gamified board-shaped quiz setting (see Figure 1). The board itself has an undetermined number of cells with "items" placed on top, and the leading actor is a robot that can be moved by a set of movement commands (i.e., go forward, stop, turn left, or turn right). The items on the cells are keys, walls, and bombs. The keys are the most important items on the board. When one is reached by the robot, it will display a question, and the rest will populate with possible answers. The goal is then to lead the robot to the correct answer cells in order to complete the quiz. The participants have, however, to avoid the obstacles represented by the other two types of items. Walls impede the robot from passing through, whereas bombs explode on contact, making the students to lose their current progress. The reason of having these obstacles and make the children lose their progress is twofold. First, to support challenges and replays, two design elements for gamification that have been shown to foster engagement, enjoyment, and productive learning experiences (Nah, Zeng, Telaprolu, Ayyappa, \& Eschenbrenner, 2014). Second, to include emotions and individual versus team responsibility of failing actions as factors that may hinder or empower the collaboration depending on how they are handled by the team. 


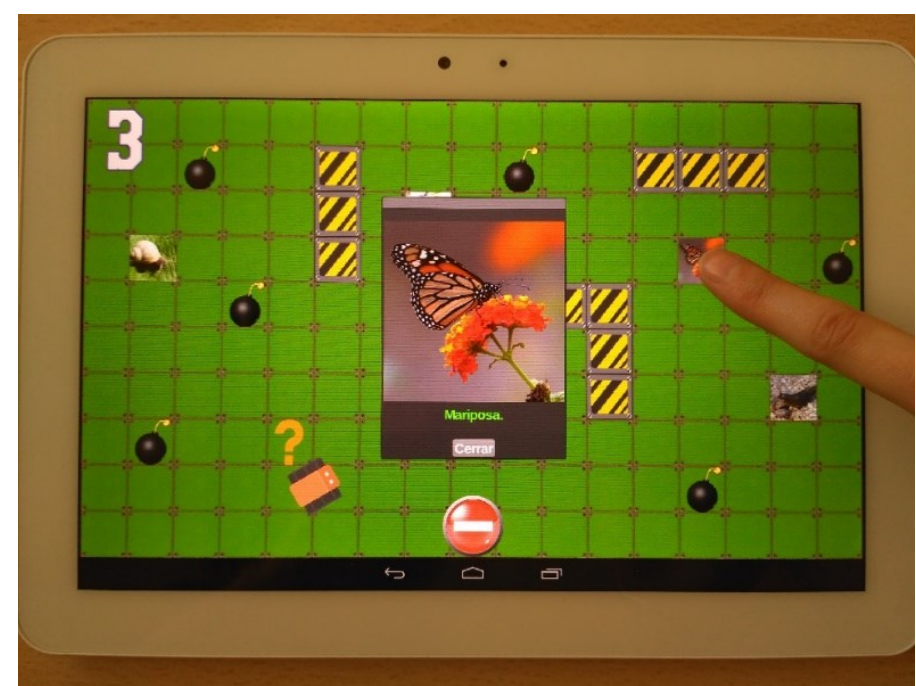

Figure 1. Quizbot's board in its tactile version. Augmented view of a selected item.

Quizbot is designed in a way that teachers can previously define through a web app the questions the children will have to solve (see Figure 2), providing the quiz with enough flexibility and the ability to redo it in case of failure. This tool is based on existing screen-based quiz-making software that also allows the definition of different question styles. Hot Potatoes ${ }^{3}$, for example, provides multiple-choice, short answer, and other hybrid types of questions. ProProfs Quiz Maker ${ }^{4}$ has multiple-choice, true/false, fill in the blank, and matching options, among others. These platforms include features that are not yet implemented in the current version of Quizbot, such as timers, personalized progress tracking, and being able to store and share the results. However, they are mainly text-based, and do not allow the definition of a board with additional game elements. Quizbot supports three different types of question styles:

- Single/Multiple Choice: The students are presented with several answers and must choose the correct one(s), visiting the cells in any order (e.g., "Which of the following energy sources are renewable?").

- Ordering: In this case, all the answers are correct but the students must visit them in a specific order (e.g., "Sort the following planets in the Solar System from smallest to biggest").

- Accumulation: These questions provide the participants with a greater freedom of choice since they can choose whichever answers they want as long as their total sum equals a certain value (e.g., "Choose from several water recipients of different sizes the ones that will fill a swimming pool having a volume of $\mathrm{X} \mathrm{\textrm {m } ^ { 3 }}$ without exceeding its capacity").

\footnotetext{
${ }^{3}$ https://hotpot.uvic.ca/

${ }^{4}$ https://www.proprofs.com/quiz-school/
} 


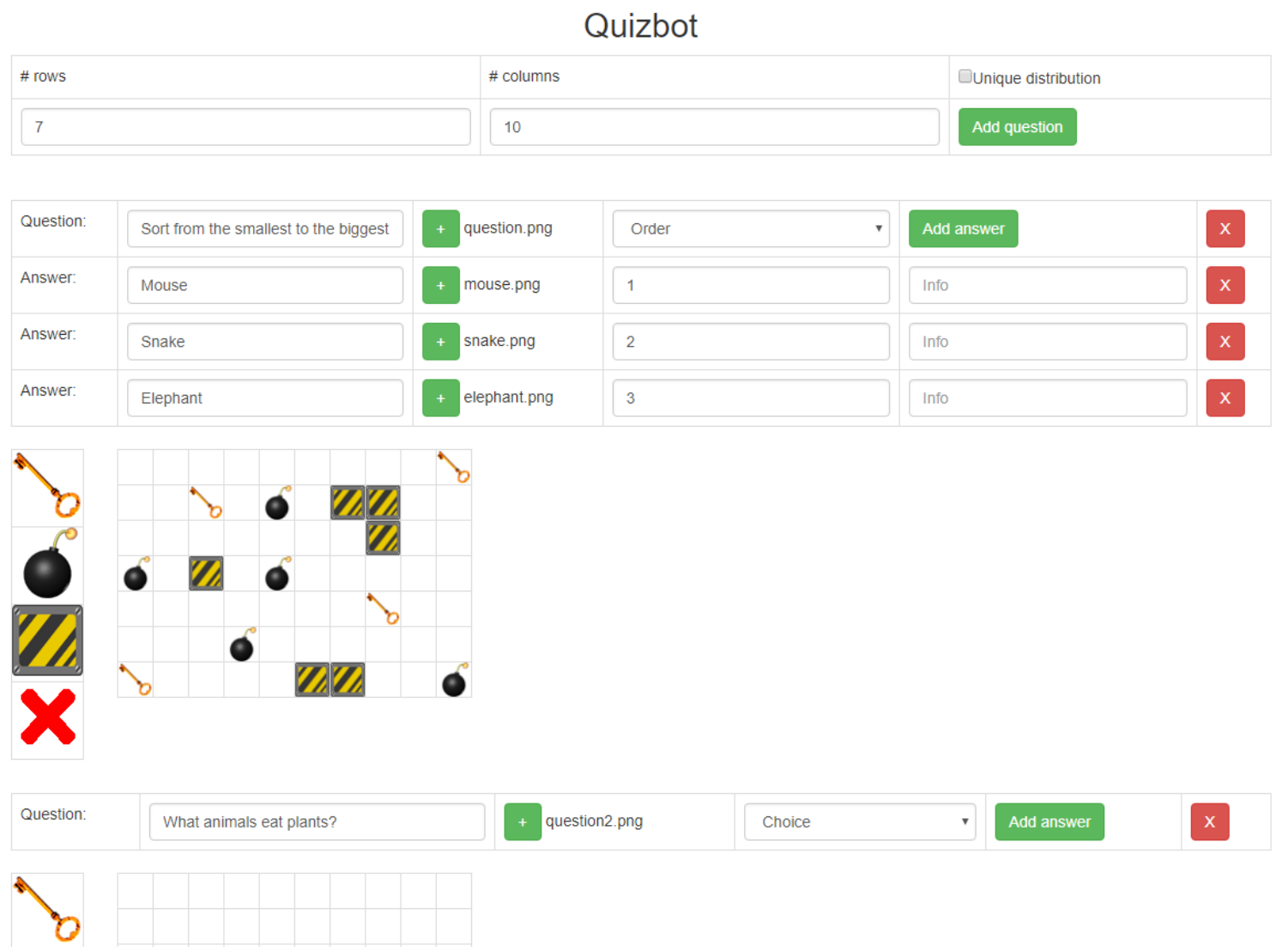

Figure 2. Quizbot contents' web editor.

In order to foster collaboration, Quizbot's main goal, the four movement commands to control the robot are split among the participants so that they are driven to cooperate and coordinate their efforts in order to plan and execute the robot's track on the board. The design rationale behind needing four users to control the robot is because working in small groups has been found very effective in collaborative learning, since it "increases each student's opportunity to interact with materials and with other students while learning. Students have more chances to speak in a small group than in a class discussion; and in that setting some students are more comfortable speculating, questioning, and explaining concepts in order to clarify their thinking" (California State Department of Education, 1985). Specifically, Quizbot is designed to meet the six conditions for successful collaborative learning identified by Szewkis et al. (Szewkis et al., 2011):

- The existence of a common goal. By providing a common goal to all participants, i.e., making them solve the same quiz, the system enables the social interactions necessary to make the students learn through collaboration (Dillenbourg, 1999).

- Coordination and communication between peers. The students need to communicate between one another and interact in the right order and at the right time in order to solve the common goal (Gutwin \& Greenberg, 2004). Since each student is in charge of giving only one movement command to the robot, they must necessarily coordinate their actions to drive the artifact to the correct answers.

- Positive interdependence between peers. The students feel connected to one another so that they feel they can only succeed as long as the rest do (Brush, 1998; Johnson \& Johnson, 1999). It can positively affect collaborative learning by animating negotiation processes and fostering joint conflict resolution (Wise et al., 2015). The distribution of the controls among the students may support positive interdependence (Järvelä, Häkkinen, Arvaja, \& Leinonen, 2004), and, as revealed in (Nam \& Zellner, 2011; Romero et al., 2012), whereas activities that are only competitive promote negative interdependence, those that include cooperation foster positive interdependence.

- Awareness of peers' work. For collaboration to work, all participants need to be able to see what the others are doing at any time, so they can receive common feedback that will support their decision making process (Gutwin \& Greenberg, 2004; Janssen, Erkens, Kanselaar, \& Jaspers, 2007). To support this, the tablets in the environment are placed on a flat surface, publicly displayed to all users at all times. 
- Individual accountability. In order to ensure their contribution, each student needs to be accountable for their actions before the others. For this, every participant must be able to see the consequences of any of their peers' actions (Janssen et al., 2007; Johnson \& Johnson, 1999; Slavin, 1996). Therefore, the distribution of the robot's movement commands is conducted publicly beforehand, and that distribution is kept constantly visible.

- Joint rewards. As all members of the team are solving the same quiz together, they get rewarded or punished alike, which makes them constantly try to improve their collaboration (Axelrod \& Hamilton, 1981; Zagal, Rick, \& Hsi, 2006).

The system is implemented in two versions: tactile and tangible. Whereas the former makes only use of mobile tablets and is used on a table, the latter adds physical objects and extends the size of the board to interact on the floor.

\subsection{Tactile Version}

As Figure 3 depicts, the tactile version of Quizbot is laid on a table with only four tablets (one per participant). Four participants are gathered around a physical table with four tablets laid on top. The interface is replicated among the devices so each student can have their personal view of the board, but a different button is placed in each display representing a different movement command for the robot: turn left (Figure 3-top-left), turn right (Figure 3-bottom-right), go forward (Figure 3-bottom-left), and stop (Figure 3-top-right). Once the robot has reached a key icon, that cell is populated with the question of the quiz and the other keys are replaced by icons representing minimized versions of the possible answers. Due to the reduced screen space, these items are not always displayed in maximized form, but each student can explore them individually on his/her tablet by touching the corresponding cell, which will show an augmented view of the item (see Figure 1). The rationale behind this configuration is to enable collocated collaborative scenarios similar to the ones that take place around tabletops, with high awareness, parallelism of actions, and fluid touch interactions on the digital displays.

Quizbot in this version is written in Java using the LibGDX 5 cross-platform game development framework. Tablets communicate through a custom NodeJS server with the websocket-based Socket.io ${ }^{6}$ library.

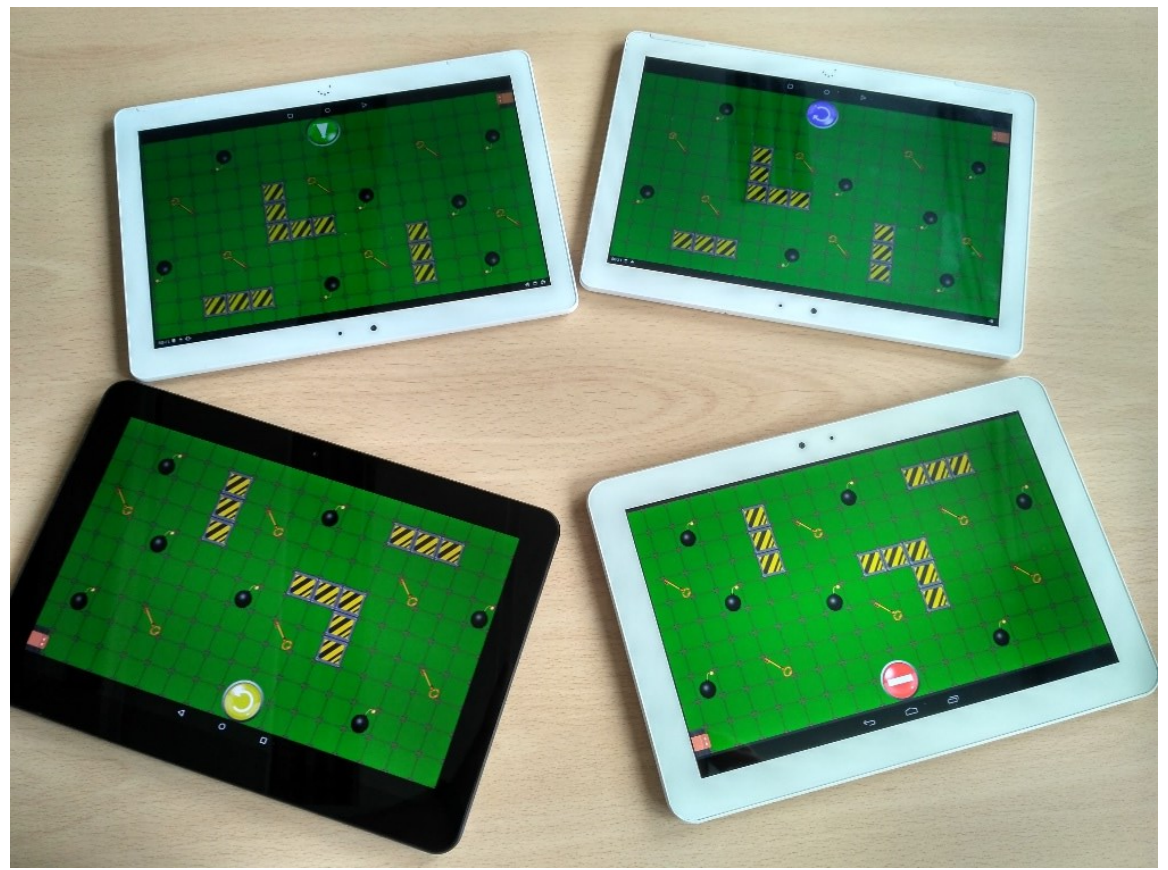

Figure 3. Instance of Quizbot in its tactile version running on four tablets.

\footnotetext{
${ }^{5}$ https://libgdx.badlogicgames.com/

${ }^{6} \mathrm{https}: / /$ socket.io/
} 


\subsection{Tangible Version}

With the aim of enabling a more dynamic approach in which physical mobility is encouraged and still provide high levels of workspace awareness, a tangible version of Quizbot was designed to be arranged on the floor (see Figure 4). Each question/answer key cell is displayed on a different tablet to facilitate the dynamic reconfiguration of digital contents as the activity progresses. They are intended to remain fixed to their location during the course of the activity, so the students can view their contents at a glance even from a distance. The board, bombs, walls, and robot are physical artefacts the participants can physically interact with. This version of Quizbot makes use of the Tangibot platform (Garcia-Sanjuan, Jaen, \& Nacher, 2017) as the physical mobile robot and its paddle-based tangible interface for its control, as it has already been proven usable for children older than 3 years old in tasks that involve following paths (Nacher, Garcia-Sanjuan, \& Jaen, 2016a). However, Tangibot's design has been slightly modified by bringing its smartphone on top (see Figure 5-left), so that it can be used to deliver video and audio feedback to the participants as different events take place (e.g., a bomb explosion, a correct or incorrect cell has been reached, etc.). Each movement command is encoded in an RFID tag enclosed in an extensible paddle as shown in Figure 5-right, which triggers the corresponding movement in the robot when the users bring the paddle close to its RFID reader. Since the manipulation of the robot takes place in the real world, the elements susceptible of triggering digital events (i.e., bombs and tablets) also have RFID tags attached underneath that are read by Tangibot's RFID reader when it approaches (see Figure 6). The robot's movements are controlled by an application residing in the robot itself and written in the graphical, block-based, Lego Mindstorms programming language ${ }^{7}$. The phone on the robot sends the RFID tags read to a dedicated NodeJS server via an Android app using the Socket.io communication library mentioned above. The same library is used by the server to send back to the phone, or to any of the tablets in the environment, the events that will display the proper video and audio feedback to the user.

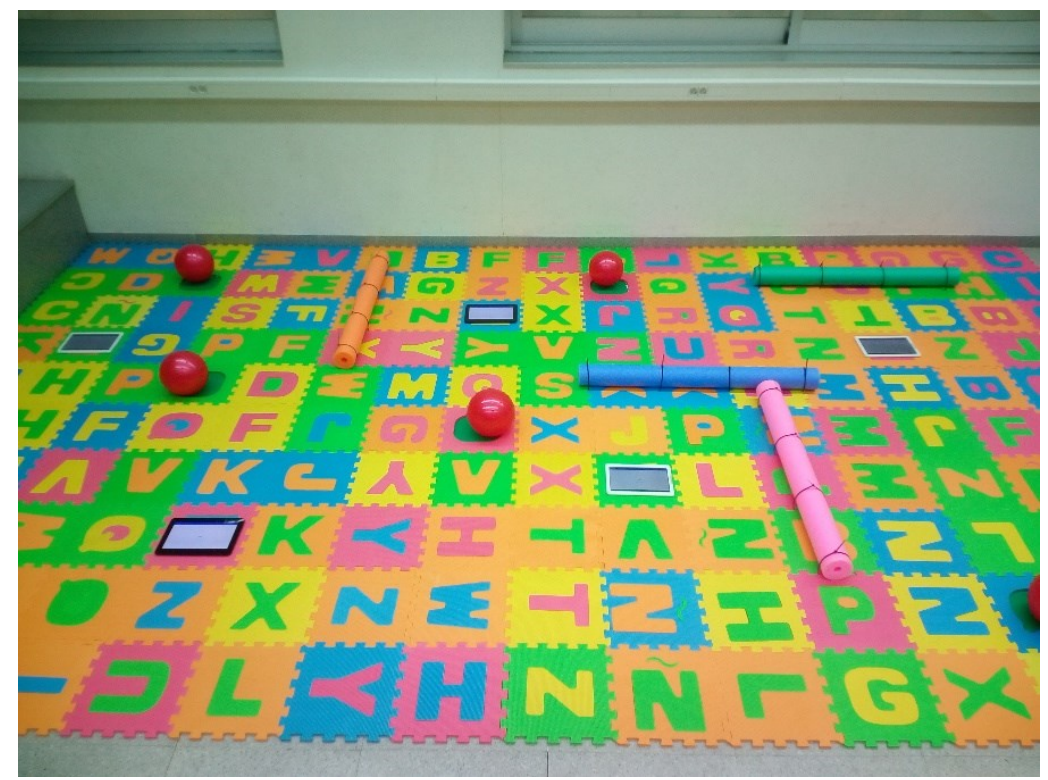

Figure 4. Instance of Quizbot in its tangible version.

\footnotetext{
${ }^{7} \mathrm{https}: / /$ www.lego.com/en-us/mindstorms/learn-to-program
} 

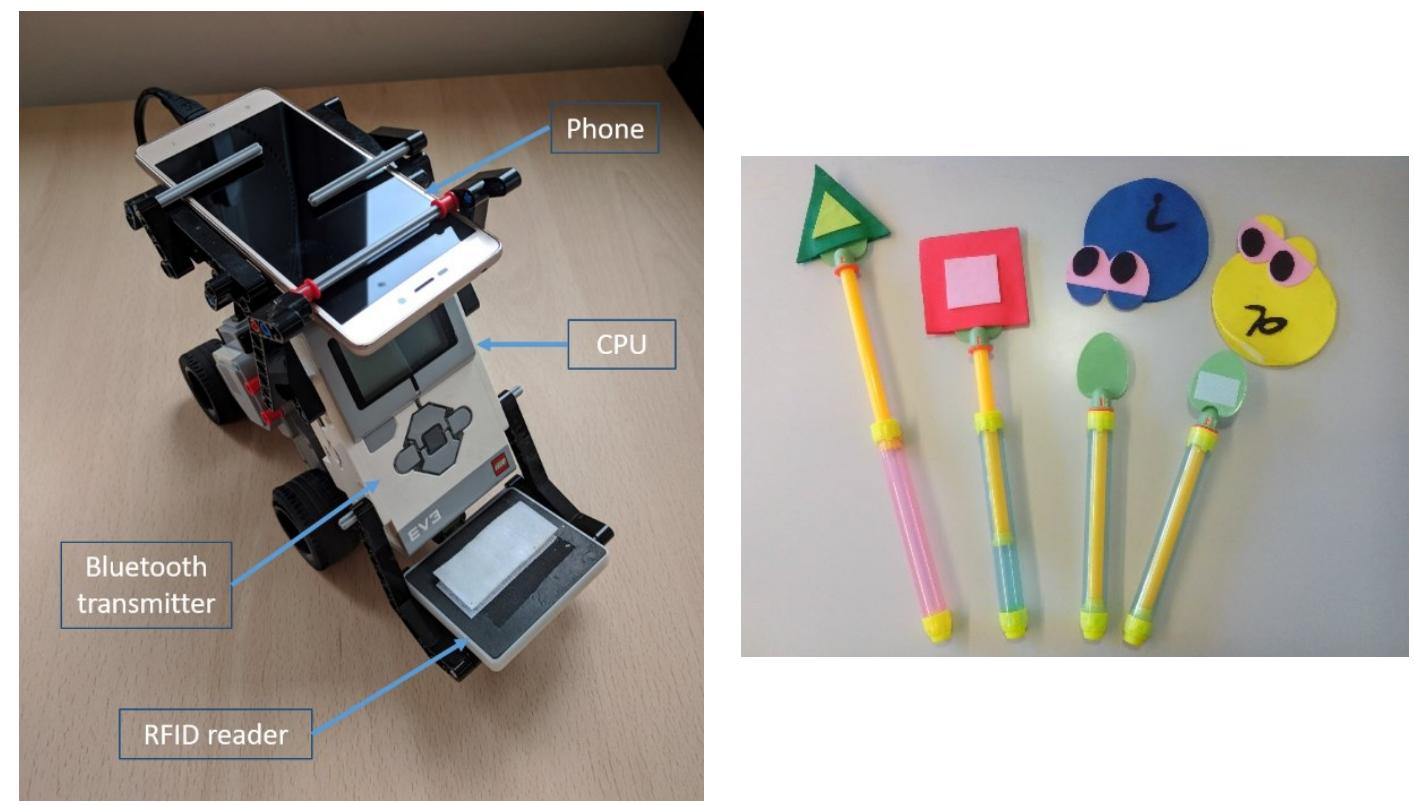

Figure 5. Tangibot's design for Quizbot (left) and paddles for its control (right).
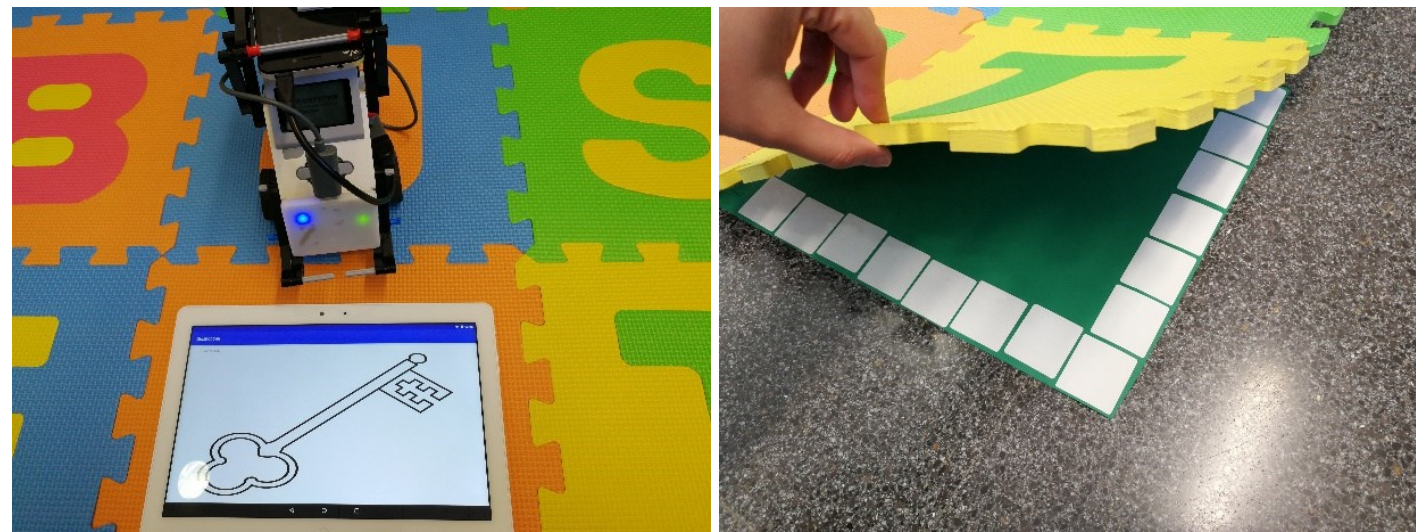

Figure 6. Tangibot approaching a tablet (left) and matrix of RFID tags placed below the tablet for Tangibot to recognize (right).

\section{Evaluation}

This section reports a study that evaluated the abilities of both tactile and tangible versions of Quizbot in terms of user experience and collaboration. Regarding the former, our goal was to assess whether our gamification approach was effective, since user experience is one of the two main goals of gamification according to Dominguez et al. (Domínguez et al., 2013). Also, as has been shown in other technological and learning contexts (Bargshady, Pourmahdi, Khodakarami, Khodadadi, \& Alipanah, 2015; Pindeh, Suki, \& Suki, 2016; Tan, Goh, Ang, \& Huan, 2016), children's user experience in terms of ease of use and fun influences their attitude to using the learning application and the effectiveness of the learning process. In this respect, three research questions were defined as follows:

RQ-UX $\mathrm{A}_{\mathrm{A}}$ : How are both versions of Quizbot perceived by the participants?

RQ-UX $\mathrm{U}_{\mathrm{B}}$ : What are the general impressions of the participants towards the activity in both platforms? RQ-UX $X_{C}$ What changes do the participants suggest to both versions of Quizbot?

To answer RQ-UX , four different hypotheses were defined:

$\mathrm{H}_{0}^{\mathrm{UXA1}}$ : There are no differences between the expected fun before using Quizbot and the fun perceived after.

$\mathrm{H}_{0}^{\mathrm{UXA2}}$ : There are no differences between both versions of the activity in terms of expected fun.

$\mathrm{H}_{0}^{\mathrm{UXA3}}$ : There are no differences between both versions of the activity in terms of perceived fun. 
$\mathrm{H}_{0}^{\text {UXA4}}$ : The participants find Quizbot easy to use.

$\mathrm{H}_{0}^{\mathrm{UXA5}}$ : There are no differences between both versions of the activity in terms of perceived ease of use.

With respect to the evaluation of collaboration, the research question addressed was the following:

RQ-C: How is the quality of the collaboration achieved by using Quizbot?

To answer this question, the nine collaboration dimensions defined by Meier et al. (Meier, Spada, \& Rummel, 2007) as listed in Table 1 were taken into consideration. These will be detailed later when the evaluation instruments are described.

\begin{tabular}{|l|l|l|}
\hline Category & Dimension \# & Dimension \\
\hline Communication & 1 & Sustaining mutual understanding \\
\hline & 2 & Dialogue management \\
\hline Joint Information Processing & 3 & Information pooling \\
\hline & 4 & Reaching consensus \\
\hline Coordination & 5 & Task division \\
\hline & 6 & Time management \\
\hline & 7 & Technical coordination \\
\hline Interpersonal Relationship & 8 & Reciprocal interaction \\
\hline Motivation & 9 & Conjoint task orientation \\
\hline
\end{tabular}

Table 1. Collaboration dimensions (grouped by category) considered to answer RC-C.

According to these dimensions the following hypothesis were defined:

$\mathrm{H}_{0}^{\text {CAi }}$ : Quizbot enables good collaboration quality in terms of Meier et al.'s i-th collaboration dimension.

$\mathrm{H}_{0}^{\mathrm{CBi}}$ : There are no differences between both versions of Quizbot in terms of Meier et al.'s i-th collaboration dimension.

Additionally, the following research question was considered with respect to the performance achieved:

RQ-P: Is there any difference between both versions of the activity in the time spent solving a quiz?

And the following hypothesis was defined to answer this question:

$\mathrm{H}_{0}^{\mathrm{P}}$ : There are no differences between both versions of Quizbot in terms of the average time spent in solving a quiz.

\subsection{Participants}

Eighty children (forty-three males and thirty-seven females) of 9-10 years of age participated in this study in the context of a summer school's activity. They were not classmates since they originated from different primary schools in Valencia (Spain).

\subsection{Apparatus}

This study took place in a classroom. Both tactile and tangible versions of Quizbot were considered. With respect to the former, four tablets were arranged on a table and the students had to sit (or stand, whichever they preferred) around. Each tablet running Quizbot had a different button to control a movement of the robot. As for the tangible version, the participants stayed on a $7 \times 4 \mathrm{~m}^{2}$ board on the floor. The game components in both platforms (i.e., bombs, walls, and keys) were placed in the same relative location. There were a total of six key cells (one question plus five possible answers), seven bombs, and twelve cells were filled with walls (see Figure 3 and Figure 4). The tablets used were all 10.1" Android capacitive tablets of different brands and models. Both the physical and virtual robots' velocities were empirically adjusted so that they spent the same time in traversing one cell $(\sim 1 \mathrm{sec})$. The educational contents used for both platforms were designed conjointly with primary school teachers who knew the children's educational curricula with the aim of making the questions affordable but still challenging enough to promote collaboration and fun. A total of thirty-six different questions were designed with contents about language, natural science, history, and geography. 


\subsection{Evaluation Instruments}

The user experience $\left(\mathrm{RQ}-\mathrm{UX}_{\mathrm{A}}\right)$ of the participants was measured via pre- and post-activity questionnaires. The fun expectancy and perception $\left(\mathrm{H}_{0}^{\mathrm{UXA} 1}, \mathrm{H}_{0}^{\mathrm{UXA} 2}, \mathrm{H}_{0}^{\mathrm{UXA} 3}\right)$ were evaluated, as well as the platform's perceived ease of use $\left(\mathrm{H}_{0}^{\mathrm{UXA} 4}\right.$ and $\left.\mathrm{H}_{0}^{\mathrm{UXA5}}\right)$, using the Smileyometer (Read, 2008; Read \& MacFarlane, 2006). This is a 5-point Likert Scale in the form of a Visual Analogue Scale (VAS), in which the different valuations (i.e., "awful", "not very good", "good", "really good", and "brilliant") are represented by smiling faces. To answer RQ-UX $\mathrm{B}_{\mathrm{B}}$ and RQ-UX $\mathrm{X}_{\mathrm{B}}$, after interacting with a platform the participants were asked to write down on a blank sheet of paper their impressions and the changes they would make (if any) to Quizbot in general or to the platform they had just used.

The rest of research questions were answered by qualitative infield observation. The time spent in solving a question (RQ-P) was calculated as the ratio between the total activity time over the number of questions solved, whereas the quality of the collaboration (RQ-C) was assessed, as pointed out above, with the questionnaire designed by Meier et al. (Meier et al., 2007). This questionnaire consists of nine dimensions associated with five different aspects of collaboration, which were filled by two independent observers after the activity in a 4-point Likert Scale ranging from -2 (very bad) to +2 (very good), with only the endpoints of the scale being named. Before the evaluation, the observers established common observation criteria based on the description from Meier et al. and adapting some dimensions to fit their actual observations, because the original descriptions were neither designed for children nor for groups of four. The different dimensions classified by the collaboration aspect they measure are described below:

- Communication

1) Sustaining mutual understanding: The students make themselves understandable to their peers by using a common language and ensure they have been understood by requesting feedback from their partners. The listeners give verbal confirmation of their understanding and ask for clarification if necessary.

2) Dialogue management: The participants let speak and listen to one another, with little time being lost due to overlaps in speech. The speakers ensure they have their partners' attention by explicitly addressing them.

- Joint information processing

3) Information pooling: The children try to gather as many pieces of information as possible. They often contribute with their own and ask the others if they do not know something.

4) Reaching consensus: The students negotiate which way to take the robot and which cells to visit and in which order, and after the discussion they come to an agreement.

- Coordination

5) Task division: The students divide their work equally among them and parallelize their actions to solve the questions.

6) Time management: The participants manage their time correctly to solve the maximum number of questions, avoiding wasting time.

7) Technical coordination: The students master the interactions necessary to successfully complete the quiz, achieving a fluent movement of the robot without bumping into obstacles. They also find strategies to guide the robot more efficiently.

- Interpersonal relationship

8) Reciprocal interaction: Partners treat one another with respect and encourage the others to contribute. While criticism is welcome, it is always related to the activity and never personal.

- Motivation

9) Conjoint task orientation: Every member of the team participates actively in the activity. They remain focused and avoid distractions, and cheer when they answer correctly. To simplify the work to the observers, this dimension has been adapted to evaluate all members of the group conjointly instead of each participant individually.

\subsection{Procedure}

The study was conducted in two sessions on two days (Monday and Thursday) as a condition imposed by the school. Before the first session began, the children were randomly arranged in groups of four, and groups were kept unaltered during the entire study. On each day, while half the groups used one version, the rest interacted with the other, and switched platforms on the second session in order to avoid carryover and learning effects. Four observers were split into pairs so that two of them monitored half the groups at the same time, observing the same children in both sessions to avoid having a pair of observers only reporting on one platform. The educational contents generated were randomly split in two sets to 
avoid repeating questions. For each session, all groups were presented with the same series of questions and answers, and in the same order.

Before starting the activity, the children were given proper instructions of the different components of Quizbot, the main objective, and how to control the robot. Then, each member of the group filled a Smileyometer with their expectations and proceeded with the activity for 30 minutes, while the two observers took notes on each group. The first quiz was a training question to help the participants familiarize with the interface and the Quizbot's rules and components. After the session, the children filled the remaining questionnaires and the observers rated the quality of the collaboration they had observed.

\subsection{Results}

\subsubsection{Performance}

The time spent by each group in solving a question was, on average, 5.48 minutes $(\mathrm{SD}=1.45)$ with the tactile version, and 4.78 minutes $(\mathrm{SD}=1.00)$ with the tangible one. A Shapiro-Wilk test revealed a normal distribution of the differences in the dependent variable between the tactile and tangible groups (statistic $=0.917, \mathrm{df}=20, p=0.087$ ). Therefore, in order to answer the research question RQ-P, a dependent t-test ( $\alpha=0.05$ ) was conducted, which revealed no significant differences between platforms for the dependent variable considered $(t(19)=1.612, p=0.123)$, hence accepting $\mathrm{H}_{0}^{\mathrm{P}}$.

\subsubsection{User Experience}

As Table 2 shows, the participants reported having high expectancies as well as high levels of perceived fun towards the activity regardless the platform used, with scores between 4 and 5 in all cases (i.e., between "really good" and "brilliant"). As the distribution of the differences between the paired observations was neither normal nor symmetrical, an exact sign test $(\alpha=0.05)$ was used to compare the differences between the expectancies they had before engaging with the system and the actual fun they reported after the activity. In this respect, both interfaces elicited a statistically significant $(p<0.05)$ decrease in the actual perception of fun from their prior expectancies (see Table 2), hence rejecting $\mathrm{H}_{0}^{\mathrm{UXA} 1}$.

\begin{tabular}{|l|l|l|}
\hline & Tactile version & Tangible version \\
\hline Avg. fun expectancy (and SD) & $4.75(0.65)$ & $4.86(0.39)$ \\
\hline Avg. fun perception (and SD) & $4.38(0.98)$ & $4.62(0.76)$ \\
\hline Median fun expectancy & 5 & 5 \\
\hline Median fun perception & 5 & 5 \\
\hline $\begin{array}{l}\text { Number of negative differences } \\
\text { (perception < expectancy) }\end{array}$ & 24 & 17 \\
\hline $\begin{array}{l}\text { Number of positive differences } \\
\text { (perception > expectancy) }\end{array}$ & 6 & 5 \\
\hline Ties (perception = expectancy) & 48 & 49 \\
\hline$p$-value & 0.002 & 0.017 \\
\hline
\end{tabular}

Table 2. Descriptive statistics and results of the exact sign test to compare the differences between fun perceived with respect to the participants' expectancies for both platforms of Quizbot.

Another exact sign test $(\alpha=0.05)$ was applied to check for differences between the tactile and tangible versions, however, no significant differences were found between platforms neither on the participants' expectancies $(p=0.359)$ nor on their perceived fun $(p=0.324)$, hence accepting $\mathrm{H}_{0}^{\mathrm{UXA} 2}$ and $\mathrm{H}_{0}^{\mathrm{UXA} 3}$, respectively.

The children's perceived ease of use towards both tactile and tangible interfaces was also analyzed as part of RQ-UX $\mathrm{A}_{\mathrm{A}}$, this being close to "really good" in both cases, which led us to accept $\mathrm{H}_{0}^{\mathrm{UXA} 4}$. For the tactile version, the perceived average ease of use was $3.94(\mathrm{SD}=1.19)$, whereas for the tangible version it was $4.09(\mathrm{SD}=1.14)$. An exact sign test $(\alpha=0.05)$ reported no significant differences between the two $(p=$ $0.178)$, hence leading to the acceptance of $\mathrm{H}_{0}^{\mathrm{UXA5}}$.

With respect to $\mathrm{RQ}-\mathrm{UX}_{\mathrm{B}}$, only $32.5 \%$ of the participants wrote down their impressions towards the activity in its tactile version, and only $25 \%$ of them towards the tangible platform. Figure 7 shows a classification of such impressions and displays the frequency of occurrence of each impression in the questionnaires. The comments made by the children were arranged in groups according to the target of 
their impressions, namely the quiz activity itself, the devices used (hardware), the board the robot moved across (board), either the buttons or the paddles to control the robot's movements (control mechanism), and the other members of the group solving the quizzes conjointly (partners). As it can be seen in the figure, the more frequent comments were about the ease of use of the tangible user interface and the nicelooking graphical user interface (around 30\% of the comments made for each platform). With respect to the tactile version, around $20 \%$ of the comments expressed the desire of the children of taking the tablets home. Even though $18.2 \%$ of the impressions explicitly stated the tactile version was easy to control, $9.1 \%$ reported the opposite. As for interacting with others, $9.1 \%$ of the impressions given reported the children having liked working in teams, whereas $18.2 \%$ were about complaints of children being yelled at by their teammates upon failing a question. The tangible platform did not receive as many impressions: there were a total of $27.8 \%$ positive comments about the activity being fun, about the children liking the questions, and about being excited to win. No comments to this respect were made for the tactile platform. Additionally, $16.7 \%$ of the impressions praised the fact of having actual objects to represent the bombs.

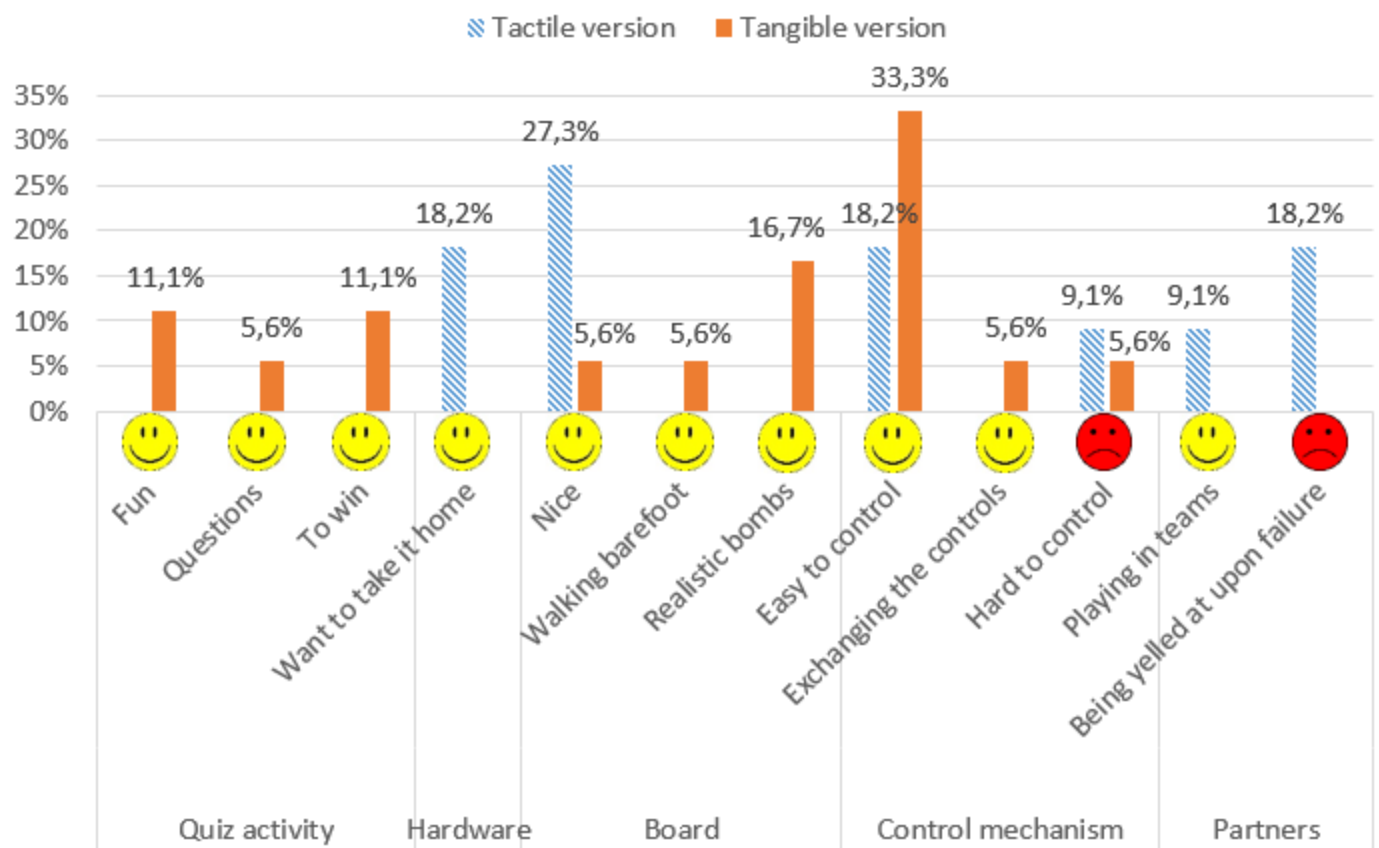

Figure 7. Frequency of participants' impressions towards both versions of Quizbot, classified by the target of the comment. The smileys indicate whether the comment was positive or negative.

The children were also asked to write down any changes they would make to any version of Quizbot (RQ-UX $\mathrm{X}_{\mathrm{C}}$ ), but only $15 \%$ and $22.5 \%$ of them suggested changes to the tactile and tangible platforms, respectively. The proposals they made are shown in Figure 8 with the frequency of their occurrence in the questionnaires. As can be seen in the chart, the more frequent proposal for each platform was explicitly to make no changes and leave the quiz and platform unaltered, however, the students suggested other improvements, such as changes to the quiz activity itself, to the robot's capabilities (robot), and to add or remove elements from the board (board). 


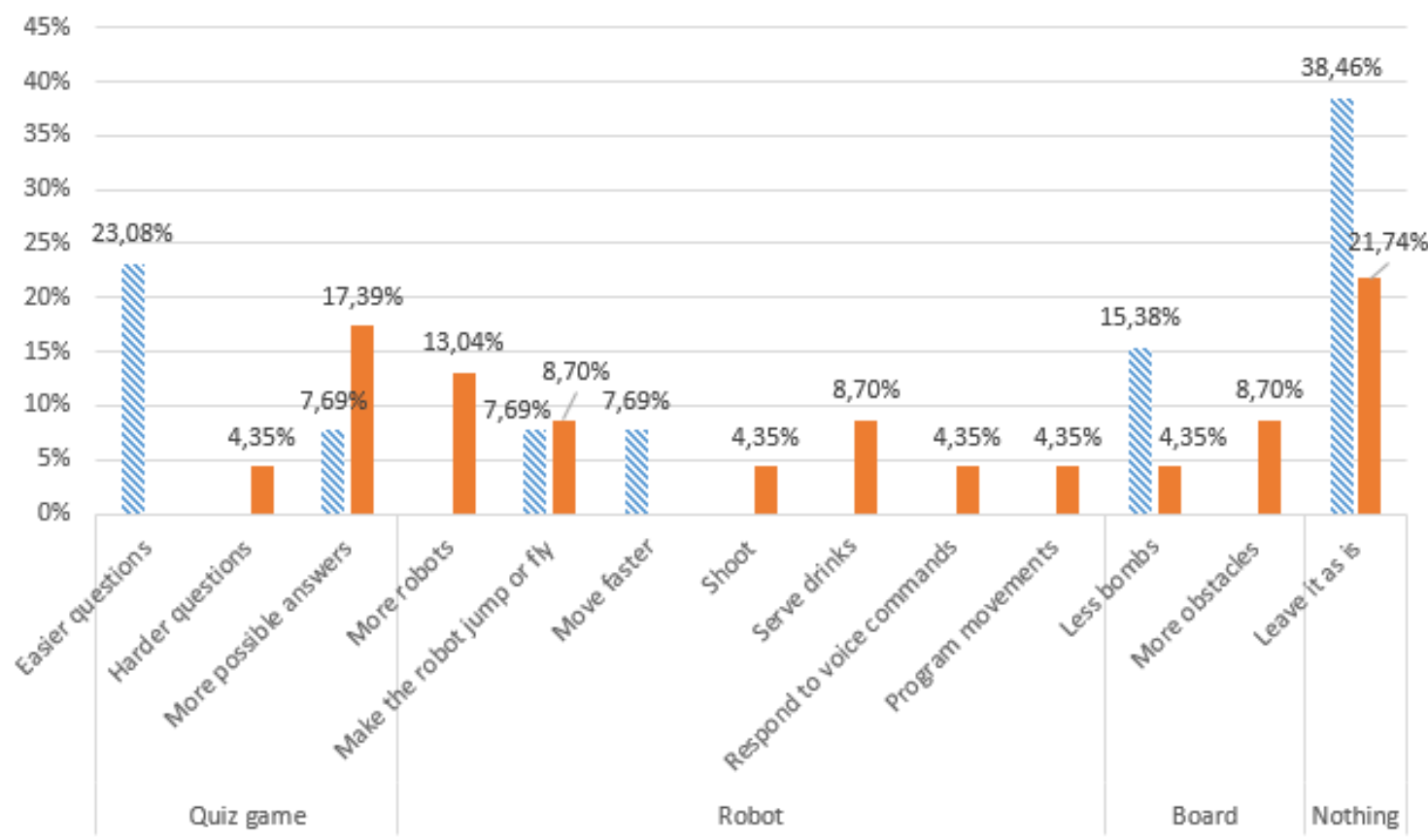

Figure 8. Frequency of participants' change proposals to both versions of Quizbot, classified by the target of the comment.

\subsubsection{Collaboration}

Figure 9 depicts the scores for each collaboration dimension and for each Quizbot version as the mean values calculated by two observers for all twenty groups of four participants. The analysis of this figure leads us to accept $\mathrm{H}_{0}^{\mathrm{C} 2}$, and $\mathrm{H}_{0}^{\mathrm{C} 4}$ to $\mathrm{H}_{0}^{\mathrm{C} 9}$, since there was, on average, good collaboration quality in terms of the corresponding dimensions (scores $>0$ ) Analogously, $\mathrm{H}_{0}^{\mathrm{C} 1}$ and $\mathrm{H}_{0}^{\mathrm{C} 3}$ are rejected. Krippendorff's $\alpha$ was used to calculate inter-rater reliability for each dimension. The results reveal good reliabilities in most of the dimensions under analysis ( $\alpha>0.8$, according to (Krippendorff, 2004)), as can be seen in Table 3. The "sustaining mutual understanding" and "dialogue management" dimensions present an absence of reliability $(\alpha=0)$ due to reduced intra-coder variability (i.e., each observer rated almost all teams equally), however, a deeper look into the ratings revealed that the observers agreed on more than $90.00 \%$ of the cases for both dimensions and both platforms.
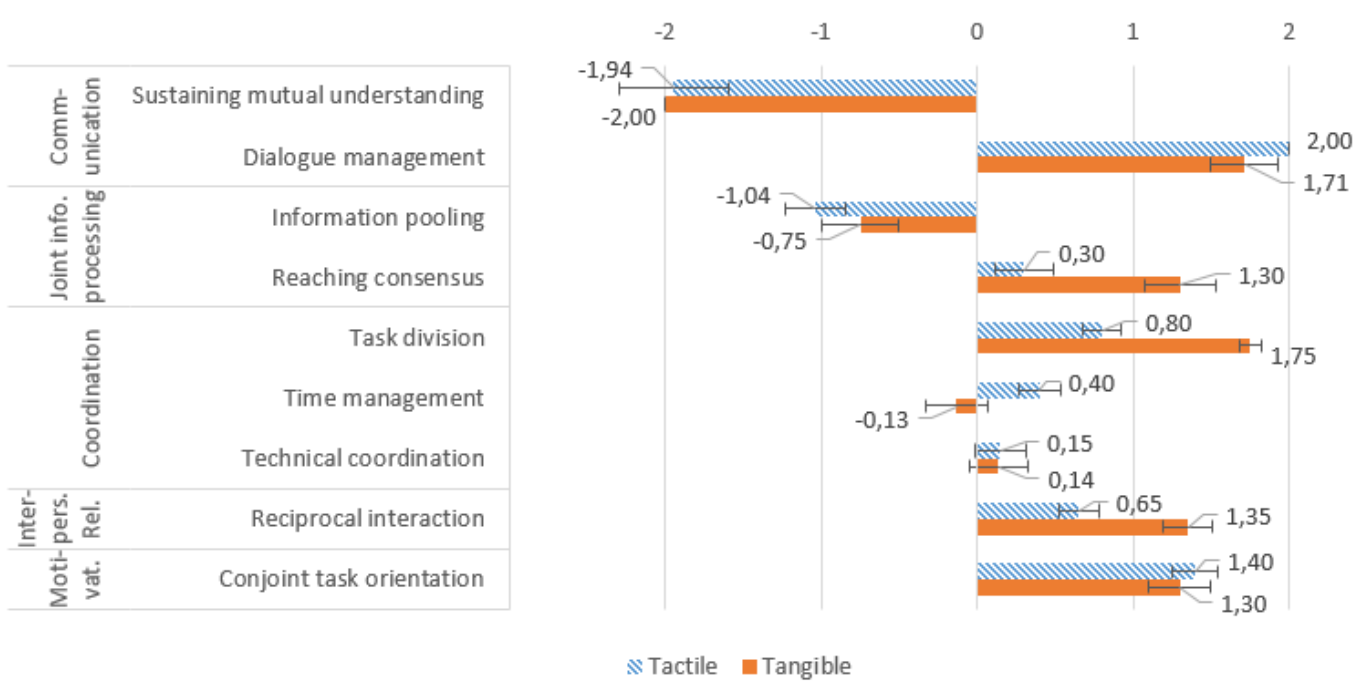

Figure 9. Scores for each communication dimension (calculated as the mean score from the two observers).

A Wilcoxon signed-rank test $(\alpha=0.05)$ applied to each dimension showed that the students behave significantly different $(p<0.05)$ with the two platforms evaluated in reaching consensus, task division, 
reciprocal interaction, and time management, with the tangible version outperforming the tactile one in all of these dimensions except the latter. This entails the rejection of $\mathrm{H}_{0}^{\mathrm{C}} 4, \mathrm{H}_{0}^{\mathrm{C} 5}, \mathrm{H}_{0}^{\mathrm{C} 6}$, and $\mathrm{H}_{0}^{\mathrm{C} 8}$, and the acceptance of $\mathrm{H}_{0}^{\mathrm{C} 1}, \mathrm{H}_{0}^{\mathrm{C} 2}, \mathrm{H}_{0}^{\mathrm{C} 3}, \mathrm{H}_{0}^{\mathrm{C} 7}$, and $\mathrm{H}_{0}^{\mathrm{C} 9}$.

\begin{tabular}{|l|l|l|l|l|}
\hline & \multicolumn{2}{|l|}{ Inter-rater reliability } & \multicolumn{2}{l|}{ Platform differences } \\
\hline Dimension & $\boldsymbol{\alpha}$ (tactile) & $\boldsymbol{\alpha}$ (tangible) & $\mathbf{Z}$ & $\boldsymbol{p}$-value \\
\hline Sustaining mutual understanding & 0.0000 & 0.0000 & 0.000 & 1.000 \\
\hline Dialogue management & 0.0000 & 0.0000 & -1.414 & 0.157 \\
\hline Information pooling & 0.8773 & 0.8120 & -0.834 & 0.404 \\
\hline Reaching consensus & 0.8276 & 0.8158 & -2.709 & 0.007 \\
\hline Task division & 1.0000 & 0.8560 & -4.363 & 0.000 \\
\hline Time management & 0.8811 & 0.9213 & -2.417 & 0.016 \\
\hline Technical coordination & 0.8495 & 0.9106 & -0.535 & 0.593 \\
\hline Reciprocal interaction & 0.8874 & 0.9824 & -3.540 & 0.000 \\
\hline Conjoint task orientation & 1.0000 & 0.9222 & -0.744 & 0.457 \\
\hline
\end{tabular}

Table 3. Krippendorff's $\alpha$ values for each communication evaluated by the two observers in each platform, and $\mathrm{Z}$ and $p$-values from the Wilcoxon test to check for differences among platforms for each dimension.

\subsection{Discussion}

The results obtained reveal Quizbot to be perceived by children as generally engaging, with fun being rated between "really good" and "brilliant" on average. From the observers' testimony, the students showed signs of being in constant state of flow, i.e., fully immersed in a feeling of energized focus, full involvement, and enjoyment in the process of the activity (Nakamura \& Csikszentmihalyi, 2008), which has often been considered a key factor to promote learning (Rathunde, 2003; Shernoff, Csikszentmihalyi, Shneider, \& Shernoff, 2003). Quantitatively, however, the fun perceived by the children was slightly but significantly lower than what they expected when first introduced to the activity. This may be related to the fact that some participants expressed their desire to make some changes, even though most of them explicitly reported not wanting to change anything. Although there were some overlaps, these changes were generally different for the two versions. For the tactile one, the students mostly expressed their desire of making it simpler, with $38.46 \%$ of the comments asking for easier questions or less bombs. Surprisingly, the tangible version, which had the same number of obstacles and in the same location, and had questions of similar difficulty, arouse opposite change wishes, since $43.48 \%$ of the changes were about having harder questions or adding more possible answers, more robots, or more obstacles. This may indicate that the participants enjoyed interacting with the tangible interface most (and therefore expected more from it). On the other hand, some children thought the robot should move faster in the tactile version, whereas none thought so for the tangible version.

The platforms considered were not found significantly different on the time the children spent solving a question nor on their ease of use, this being evaluated by children close to "really good" in terms of Read's Smileyometer. This result was not completely unexpected for the tactile version since children nowadays are quite accustomed to using mobile tablets, yet it reinforces previous findings in the literature about tangible user interfaces being very intuitive and easy to use. The ease of use of the paddle-based control mechanism might have surprised the children as well, seeing that it was the most frequent positive impression remarked towards the tangible platform with a $33.3 \%$ of occurrence.

Results also indicate that both versions of Quizbot support in general good collaboration quality, with all dimensions but "sustaining mutual understanding", "information pooling", and "time management" in the tangible version being rated positively. A discussion with the observers revealed some insights about why the students performed worse in these dimensions. "Information pooling" was rated close to "bad". Even though children sometimes asked their teammates for help, their explanations were not very elaborate, and mostly consisted of giving orders to one another. "Sustaining mutual understanding" received the lowest scores, being rated close to "very bad". This was due to the children not being concerned about whether their peers understood or not their explanations. When children expressed their opinion, they moved on with the activity, and if they later found out that their peers had not understood them, they repeated their explanation again. The results on this dimension could suggest either a deficiency of the system in supporting collaboration, or a limitation of the questionnaire defined by Meier et al. (Meier et al., 2007) when used with children, since some dimensions were initially devised to be applied to adults, who have higher communication skills. "Time management" in the tangible version, although close to 0 (neutral), was also rated negatively. This was probably due to the novelty effect the platform had on the children, which made them spend much time playing with the physical props on the board and running 
around. In a few cases, the children would make the robot purposely collide with the blocks just for fun. There were also cases where they actually broke the robot due to rough handling (by colliding or moving the robot manually). These behaviors could have been influenced by children's previous experience when playing with physical toys. Surprisingly, the time to solve the questions does not significantly differ between platforms, which can be explained by the children being more precise in controlling the robot and not colliding as much with the walls and bombs when using the tangible version, which, as reported by the observers, was more frequent in the tactile version. Besides "time management", both versions of Quizbot did show significant differences on several collaboration dimensions, namely "reaching consensus", "task division", and "reciprocal interaction", in which the tangible platform outperformed the tactile one. The reason why reciprocal interaction was significantly perceived lower in the tactile version could also be explained by the fact that the participants seemed to collide more with bombs, hence losing their progress, which caused the children to blame one another. These reprimands and critics were not always constructive, and would had probably irritated the participants. This would also explain why $18.2 \%$ of the impressions regarding the tactile interface were about children disliking being yelled at when making a mistake. Task division being significantly better in the tangible interface is probably associated with the fact that each tablet represented a key (question/answer) cell in the system and they were scattered on a big board the children could move around. A frequent pattern emerged in this platform: when a question appeared, the children would disperse on the board to explore the answers, and would inform the others about the ones they had seen, thereby parallelizing more their work. In the tactile platform, however, they tended to explore all the cells individually, and then negotiate which ones to visit. This is probably due to them being accustomed to use mobile devices individually. Finally, reaching consensus was also perceived significantly higher in the tangible version than in the tactile one. This was so because in the tactile version the students tended to negotiate only which cells to visit but in the tangible version they also negotiated which path to take the robot on in order to drive it through the shortest or safest (bomb-free) way, and helped their arguments by moving themselves on the board. This was harder to achieve in the tactile version because the board was embedded in a small screen, even though it was sometimes observed that some children stood up and pointed the way on each partner's tablet.

It was also observed during the activity that Quizbot's design seemed to enable meeting all six conditions for successful collaborative learning identified by Szewkis et al. (Szewkis et al., 2011), namely having a common goal, joint rewards, awareness of the others' work, individual accountability, coordination and communication between peers, and positive interdependence. Three components of its design were responsible for this: the rules, the layout and interaction of/with the different props and devices, and the collaborative relationships supported. The different constraints and rules, including having a common goal and joint rewards for all participants, made collaboration fun. As reported above, the children showed signs of being in state of flow and enjoyed working with others. Having a flat layout in which all elements were distributed on a public surface for all users to see and access enhanced workspace awareness, as expected. It was observed that children frequently referred to certain parts of the board by pointing at them with their finger or by referring to them using demonstratives (e.g., "let's go there"), which simplified communication and helped them maintain their focus. The interaction with the platform via distributed controls among the participants facilitated the users being accountable for their actions before the rest. Indeed, they were constantly aware of which partner was in charge of which movement command, which they often used to address one another (e.g., "now you turn right!", "where is the one who stops it?"). This design to promote awareness and individual accountability sometimes led to the situation described above of having a child being recriminated a failure, but it also enabled congratulations upon success and situations in which the children identified a potential "expert" in a given topic because they had previously answered correctly a similar quiz, which increased the group's performance. Finally, Quizbot fostered collaborative relationships which supported coordination and communication (discussed above) as well as positive interdependence. The latter emerged not only because the constraints prevented the children from completing a quiz individually or because the information and controls were distributed, but as a result of the students feeling as part of a team, as suggested by multiple uses of first person plural forms such as "we won!", "we need to go there", or "we should first think about which ones are correct".

In general, it can be inferred from the study conducted that Quizbot provides a fun and engaging way to effectively support collaboration and exploration, which, according to Price et al. (Price et al., 2003) are key to successfully develop playful learning activities. Reflection is another aspect which seems not to be given enough importance in the activities conducted, as the poor results in time management might suggest that they did not take enough time to think the answers through. Some patterns can be extracted 
from the observers' testimony with respect to the procedure used to solve the quizzes. Whenever a new quiz would start there was exploration. Before selecting an answer, the children would visit all the possibilities before starting the planning process. This, as reported above, was observed most frequently on the tangible platform. After exploring the solutions, there was planning, when all the groups would stop and discuss which path to take to get to the next question. During the exploration and planning processes, a lot of knowledge sharing also took place, especially if a child was sure of an answer or if someone asked a question. Whenever there were discrepancies, the children would discuss which ones to visit, and they often reached a consensus. Sometimes, one of them would take on a leadership role and order all the movements. Most of the children would shout for the robot to be stopped, especially when it was about to collide with a bomb, making some of them either avoid that movement command or purposely asking for it, but the group leaders would shout out all the movements, telling the others when to go forward or when to turn. Other roles identified by Fan (S. B. Fan, 2010) as usually formed during this type of activity were also observed to different degrees in each group. These roles are, Brainstormer, Critic, Supporter, and Team Wrangler. In some groups, children would be fed up with waiting for someone to perform a movement command and would either invade the other's workspace (in the tactile version) or grasp the other child's hand to force them to perform the command. There were also cases in which one of the participants would sabotage the rest by constantly turning the robot or stopping it as soon as it started moving. In these cases, the other children would either tell them off or, in a few cases, physically stop them by grabbing their hand. There were several groups with good coordination and groups with bad coordination. Sometimes a person would say the correct answer but the others would ignore them, causing this participant to sulk and ignore the game. In some cases, after answering wrongly, part of the group would sulk and momentarily stop the activity. There were also cases where someone would try to cheer up the rest of the group and encourage them to try another answer.

The results also suggest that some changes could be made to Quizbot's design in both platforms in order to make it more appealing and to better support collaborative learning. First, the teacher should design both the questions and the board layout (i.e., obstacles) according to different difficulty levels, so that the students could move on to harder levels progressively. Second, additional capabilities to the robot (e.g., jumping, moving at different speeds, etc.) should be considered and studied, for it might increase fun in detriment of content comprehension (Achtman, Green, \& Bavelier, 2008; Aleven, Myers, Easterday, \& Ogan, 2010). Similarly, having a robot per user acting as an avatar might increase children's motivation, but the gamification dynamics should be revisited to still support Szewkis et al.'s requirements for collaborative learning (Szewkis et al., 2011), such as having a common goal. In order to improve the quality of the communication in terms of sustaining mutual understanding and information pooling, as well as to better support reflection, the quizzes defined could be more open-ended or require a more elaborate resolution procedure for the children to have more time to think about the answers, and expose and discuss their opinions. With respect to the tactile version of the system, task division and reaching consensus might be improved by having an extended-continuous logical view of the multi-tablet environment (Garcia-Sanjuan et al., 2016b), i.e., having each display to show a partial view of the board. This way the elements could be bigger and the children might parallelize their explorations and discuss alternative paths for the robot as it happened with the tangible version. Additionally, a combination of both platforms presented in this study could be developed in order to create a hybrid tactile/tangible version of Quizbot to be laid on a table. A smaller physical robot would be moved among the tablets, and, by using technology to track the tablets on the table (e.g., (Garcia-Sanjuan, Jaen, \& Nacher, 2016a; Rädle, Jetter, Marquardt, Reiterer, \& Rogers, 2014)), the whole table would serve as the board whereas the tablets act as "peepholes" that show the digital world as they are moved, thereby having an extendeddiscontinuous logical view of the MDE (Garcia-Sanjuan et al., 2016b).

\section{Limitations}

This study presents some limitations that should be acknowledged. In particular, the design adopted could raise some issues. Firstly, prior experience with tactile and tangible interactions as well as the novelty effect on the tangible platform could have affected general user experience and behaviors, and different results might arise with more exposure to the tangible interface. Secondly, the fun factor could diminish over time, which could impact the acceptance of the system. Thirdly, the mechanics of driving the robot from questions to answers could distract the students from the educational contents. Fourhtly, it is not clear whether enforcing collaboration through the distribution of controls is the most effective way of fostering it among children: some authors have found that enforced collaboration effectively promotes it (Battocchi et al., 2009) and even has an impact on children with Autism Spectrum Disorders in terms of fostering positive social interactions (Ben-Sasson, Lamash, \& Gal, 2013); however, others like Benford et al. (Benford et al., 2000) suspect that encouraging collaboration rather than enforcing it might entail long- 
term educational gains when children discover collaboration for themselves. And, finally, it is also not clear whether having a generic tangible interface independent of the educational contents favors collaborative learning effectively beyond the facilitation of content management. All these issues would need to be explored further in future work.

The evaluation was conducted under constraints imposed by the school, which prevented us from obtaining potentially valuable information. For example, we were forbidden to record the sessions, which limited the data available to the observers' notes and comments. In this respect, several observations, such as the one referring to the children being in state of flow during the activity, would need further exploration and proper measurement (Kiili, Lainema, de Freitas, \& Arnab, 2014). Also, a formal evaluation would be needed to ascertain whether Quizbot effectively supports meeting the six conditions for successful collaborative learning identified by Szewkis et al. (Szewkis et al., 2011). Group dynamics were also constrained, as the participants did not know each other. Previous research suggests that having different group dynamics (e.g. groups of friends, groups of strangers, or mixed) can affect collaborative learning (M. Fan, Antle, Neustaedter, \& Wise, 2014; Meerbeek, Bingley, Rijnen, \& van den Hoven, 2010).

Finally, the differences found between both interaction techniques must be interpreted with caution, as they refer to the platforms evaluated as a whole and not simply to the interaction modality (tactile vs. tangible). This interaction modality factor was not completely isolated and others could have an impact, e.g., the size of the elements, the ability to physically move, or having one single view of the workspace versus four replicated ones. However, this confounding arose from trying to make the two versions realistic and look like the actual scenarios of these characteristics in a classroom.

\section{Conclusions and Future Work}

This work has presented Quizbot, a collaborative gamified activity in the form of a tablet-based MDE that consists of solving quizzes by conjointly driving a robot. It comes in two interaction modalities: tactile and tangible. Whereas the tactile version is played with different tablets arranged on a table the players gather around, the tangible version combines the screens with physical props scattered on the floor. Both versions seek to take advantage of handheld devices to build affordable, improvised, scalable settings that provide intuitive, fluid, and simultaneous interactions; high workspace awareness; and, in the case of the tangible platform, physical mobility; all to enable collaborative learning.

A study conducted with eighty primary-schooled children has revealed that both platforms are equally valid to provide a fun experience, and no interaction mechanism has emerged as significantly better than the other in terms of performance or ease of use. An analysis of the quality of the collaboration around nine dimensions has revealed both versions enabling good collaboration in general, with the tangible platform outperforming the tactile one in being able to make the children reach consensus after a discussion, split and parallelize work, and treat each other with more respect. Nevertheless, it has also been observed that the participants managed their time more poorly with the tangible platform, probably due to being overwhelmed by having so many physical props to interact with.

From the results obtained, several design changes to the educational contents and the interactive elements have been proposed. These consist of presenting the quizzes to the children in increasing level of difficulty, and making the questions either open-ended or that require an elaborate resolution procedure to trigger more conversations. Additionally, other major changes have been proposed that should be properly studied in terms of their suitability to promote collaborative learning. These include extending the robot's functionality with the ability to jump or to move at different speeds, adding more robots to the environment, and also to combine both interaction modalities into a hybrid tactile-tangible platform to be played on a table with location-aware tablets.

In future work, the design changes described in Section 4.6 should be explored in order to successfully implement Quizbot in schools. Also, to strengthen the present results, further studies should be conducted to evaluate the impact of both versions of the system on other aspects of collaborative learning (e.g., knowledge acquisition), and to tackle the issues elicited in Section 5. The quality of collaboration could also be analyzed from the children's perspective. Even though, to the best of our knowledge, there is no validated questionnaire for children aged 9-10 to self-assess their collaborative experience, some qualitative measures could be taken, e.g., by analyzing students' reports. Additionally, it would be interesting to study the relationship between user acceptance and collaborative performance, perhaps measuring whether there is a correlation between the two, as well as to delve deeper into the different 
ways young students collaborate in multi-tablet co-located environments. Finally, further research could be conducted to assess how tangible and tactile solutions meet the different needs posed by different learning settings and students; in particular, to support inclusive learning.

\section{References}

Achtman, R. L., Green, C. S., \& Bavelier, D. (2008). Video games as a tool to train visual skills. Restorative Neurology and Neuroscience, 26(4-5), 435-46. Achtman2008. Retrieved from http://www.ncbi.nlm.nih.gov/pubmed/18997318

Aleven, V., Myers, E., Easterday, M., \& Ogan, A. (2010). Toward a Framework for the Analysis and Design of Educational Games. In 2010 Third IEEE International Conference on Digital Game and Intelligent Toy Enhanced Learning (pp. 69-76). Aleven2010, IEEE. http://doi.org/10.1109/DIGITEL.2010.55

Amrein, A. L., \& Berliner, D. C. (2002). High-Stakes Testing \& Student Learning. Education Policy Analysis Archives, 10(18). http://doi.org/10.14507/epaa.v10n18.2002

Antle, A. N. (2013). Exploring how children use their hands to think: an embodied interactional analysis. Behaviour \& Information Technology, 32(9), 938-954. http://doi.org/10.1080/0144929X.2011.630415

Antle, A. N., \& Wise, A. F. (2013). Getting Down to Details: Using Theories of Cognition and Learning to Inform Tangible User Interface Design. Interacting with Computers, 25(1), 1-20. http://doi.org/10.1093/iwc/iws007

Axelrod, R., \& Hamilton, W. D. (1981). The evolution of cooperation. Science, 211(4489), 1390-1396. Axelrod1981. Retrieved from http://www.ncbi.nlm.nih.gov/pubmed/7466396

Ballagas, R., Rohs, M., Sheridan, J., \& Borchers, J. (2004). BYOD: Bring Your Own Device. In Proceedings of the Workshop on Ubiquitous Display Environments. Ballagas2004, Nottingham, UK.

Bargshady, G., Pourmahdi, K., Khodakarami, P., Khodadadi, T., \& Alipanah, F. (2015). The Effective Factors on User Acceptance in Mobile Business Intelligence. Jurnal Teknologi, 72(4). Bargshady2015. http://doi.org/10.11113/jt.v72.3913

Batsila, M., \& Tsihouridis, C. (2017). "Let's Go... Kahooting” - Teachers' Views on C.R.S. for Teaching Purposes. In 20th International Conference on Interactive Collaborative Learning (pp. 563-571). Springer. http://doi.org/10.1007/978-3-319-73210-7_66

Battocchi, A., Pianesi, F., Tomasini, D., Zancanaro, M., Esposito, G., Venuti, P., ... Weiss, P. L. (2009). Collaborative Puzzle Game: a tabletop interactive game for fostering collaboration in children with Autism Spectrum Disorders (ASD). In Proceedings of the ACM International Conference on Interactive Tabletops and Surfaces (pp. 197-204). ACM. http://doi.org/10.1145/1731903.1731940

Ben-Sasson, A., Lamash, L., \& Gal, E. (2013). To enforce or not to enforce? The use of collaborative interfaces to promote social skills in children with high functioning autism spectrum disorder. Autism, 17(5).

Benford, S., O’Malley, C., Simsarian, K. T., Stanton, D., Sundblad, Y., Taxén, G., ... Neale, H. (2000). Designing storytelling technologies to encouraging collaboration between young children. In Proceedings of the SIGCHI conference on Human factors in computing systems (pp. 556-563). ACM. http://doi.org/10.1145/332040.332502

Betts, B. W., Bal, J., \& Betts, A. W. (2013). Gamification as a tool for increasing the depth of student understanding using a collaborative e-learning environment. International Journal of Continuing Engineering Education and Life-Long Learning, 23(3/4), 213-228. http://doi.org/10.1504/IJCEELL.2013.055405

Blunt, J. R., \& Karpicke, J. D. (2014). Learning with retrieval-based concept mapping. Journal of Educational Psychology, 106(3), 849-858. Blunt2014. http://doi.org/10.1037/a0035934 
Bock, M., Fisker, M., Topp, K. F., \& Kraus, M. (2015). Tangible Widgets for a Multiplayer Tablet Game in Comparison to Finger Touch. In Proceedings of the 2015 Annual Symposium on ComputerHuman Interaction in Play (pp. 755-758). Bock2015, New York, New York, USA: ACM. http://doi.org/10.1145/2793107.2810269

Boyle, E. A., Hainey, T., Connolly, T. M., Gray, G., Earp, J., Ott, M., ... Pereira, J. (2016). An update to the systematic literature review of empirical evidence of the impacts and outcomes of computer games and serious games. Computers \& Education, 94, 178-192. Boyle2016. http://doi.org/10.1016/j.compedu.2015.11.003

Brush, T. A. (1998). Embedding cooperative learning into the design of integrated learning systems: Rationale and guidelines. Educational Technology Research and Development, 46(3), 5-18. Brush1998. http://doi.org/10.1007/BF02299758

California State Department of Education. (1985). Mathematics Framework for California Public Schools, Kindergarten Through Grade Twelve. CaliforniaStateDepartmentofEducation1985, Sacramento, CA, USA: California Deparment of Education.

Catala, A., Garcia-Sanjuan, F., Jaen, J., \& Mocholi, J. A. (2012). TangiWheel: A Widget for Manipulating Collections on Tabletop Displays Supporting Hybrid Input Modality. Journal of Computer Science and Technology, 27(4), 811-829. Catala2012.

Catala, A., Garcia-Sanjuan, F., Pons, P., Jaen, J., \& Mocholi, J. A. (2012). Agoras: Towards Collaborative Game-Based Learning Experiences on Surfaces. In International Conference on Cognition and Exploratory Learning in Digital Age. Catala2012c.

Cheong, C., Cheong, F., \& Filippou, J. (2013a). Quick Quiz: A Gamified Approach for Enhancing Learning. In PACIS 2013 Proceedings. Retrieved from https://aisel.aisnet.org/pacis2013/206

Cheong, C., Cheong, F., \& Filippou, J. (2013b). Using Design Science Research to Incorporate Gamification into Learning Activities. PACIS 2013 Proceedings.

Chipman, G., Fails, J. A., Druin, A., \& Guha, M. L. (2011). Paper vs. tablet computers: a comparative study using Tangible Flags. In Proceedings of the 10th International Conference on Interaction Design and Children (pp. 29-36). Chipman2011, New York, New York, USA: ACM. http://doi.org/10.1145/1999030.1999034

Connolly, T. M., Boyle, E. A., MacArthur, E., Hainey, T., \& Boyle, J. M. (2012). A systematic literature review of empirical evidence on computer games and serious games. Computers \& Education, 59(2), 661-686. Connolly2012. http://doi.org/10.1016/j.compedu.2012.03.004

de-Marcos, L., Garcia-Lopez, E., \& Garcia-Cabot, A. (2016). On the effectiveness of game-like and social approaches in learning: Comparing educational gaming, gamification \& social networking. Computers \& Education, 95, 99-113. http://doi.org/10.1016/j.compedu.2015.12.008

de Sousa Borges, S., Durelli, V. H. S., Reis, H. M., \& Isotani, S. (2014). A systematic mapping on gamification applied to education. In Proceedings of the 29th Annual ACM Symposium on Applied Computing (pp. 216-222). New York, New York, USA: ACM Press. http://doi.org/10.1145/2554850.2554956

Deci, E. L., \& Ryan, R. M. (1990). A Motivational Approach to Self: Integration in Personality. In Nebraska Symposium on Motivation.

Deterding, S., Dixon, D., Khaled, R., \& Nacke, L. (2011). From game design elements to gamefulness: defining "gamification." In Proceedings of the 15th International Academic MindTrek Conference on Envisioning Future Media Environments (pp. 9-15). Deterding2011, New York, New York, USA: ACM. http://doi.org/10.1145/2181037.2181040

Dillenbourg, P. (1999). What do you mean by “collaborative learning”? In P. Dillenbourg (Ed.), Collaborative-learning: Cognitive and Computational Approaches (pp. 1-19). Dillenbourg1999, Elsevier. 
Domínguez, A., Saenz-de-Navarrete, J., De-Marcos, L., Fernández-Sanz, L., Pagés, C., \& MartínezHerráiz, J.-J. (2013). Gamifying learning experiences: Practical implications and outcomes. Computers \& Education, 63, 380-392. http://doi.org/10.1016/j.compedu.2012.12.020

Eales, R. T. J., Hall, T., \& Bannon, L. J. (2002). The motivation is the message: comparing CSCL in different settings. In CSCL '02 Proceedings of the Conference on Computer Support for Collaborative Learning: Foundations for a CSCL Community (pp. 310-317). International Society of the Learning Sciences.

Fails, J. A., Druin, A., Guha, M. L., Chipman, G., Simms, S., \& Churaman, W. (2005). Child's play: a comparison of desktop and physical interactive environments. In Proceeding of the 2005 conference on Interaction design and children (pp. 48-55). Fails2005, New York, New York, USA: ACM. http://doi.org/10.1145/1109540.1109547

Falloon, G., \& Khoo, E. (2014). Exploring young students' talk in iPad-supported collaborative learning environments. Computers \& Education, 77, 13-28. Falloon2014. http://doi.org/10.1016/j.compedu.2014.04.008

Fan, M., Antle, A. N., Neustaedter, C., \& Wise, A. F. (2014). Exploring How a Co-dependent Tangible Tool Design Supports Collaboration in a Tabletop Activity. In Proceedings of the 18th International Conference on Supporting Group Work (pp. 81-90). New York, New York, USA: ACM Press. http://doi.org/10.1145/2660398.2660402

Fan, S. B. (2010). Roles in Online Collaborative Problem Solving. In 2010 IEEE Symposium on Visual Languages and Human-Centric Computing (pp. 265-266). Fan2010, IEEE. http://doi.org/10.1109/VLHCC.2010.51

Finkelstein, N. D., Adams, W. K., Keller, C. J., Kohl, P. B., Perkins, K. K., Podolefsky, N. S., ... LeMaster, R. (2005). When learning about the real world is better done virtually: A study of substituting computer simulations for laboratory equipment. Physical Review Special Topics Physics Education Research, 1, 010103.1-010103.8. Finkelstein2005. http://doi.org/10.1103/PhysRevSTPER.1.010103

Fitz-Walter, Z., Tjondronegoro, D., Koh, D., \& Zrobok, M. (2012). Mystery at the library: encouraging library exploration using a pervasive mobile game. In Proceedings of the 24th Australian Computer-Human Interaction Conference (pp. 142-145). Fitz-Walter2012, New York, New York, USA: ACM. http://doi.org/10.1145/2414536.2414561

Garcia-Sanjuan, F., Jaen, J., \& Nacher, V. (2016a). From Tabletops to Multi-Tablet Environments in Educational Scenarios: A Lightweight and Inexpensive Alternative. In Proceedings of the 16th International Conference on Advanced Learning Technologies (pp. 100-101). GarciaSanjuan2016b, IEEE.

Garcia-Sanjuan, F., Jaen, J., \& Nacher, V. (2016b). Toward a General Conceptualization of Multi-Display Environments. Frontiers in ICT, 3, 20:1-20:15. Garcia-Sanjuan2016d. http://doi.org/10.3389/fict.2016.00020

Garcia-Sanjuan, F., Jaen, J., \& Nacher, V. (2017). Tangibot: A tangible-mediated robot to support cognitive games for ageing people-A usability study. Pervasive and Mobile Computing, 34, 91105. Garcia-Sanjuan2016f. http://doi.org/10.1016/j.pmcj.2016.08.007

Gire, E., Carmichael, A., Chini, J. J., Rouinfar, A., Rebello, S., Smith, G., \& Puntambekar, S. (2010). The effects of physical and virtual manipulatives on students' conceptual learning about pulleys. In Proceedings of the 9th International Conference of the Learning Sciences (Vol. 1, pp. 937-943). Gire2010, International Society of the Learning Sciences.

Gutwin, C., \& Greenberg, S. (1998). Effects of Awareness Support on Groupware Usability. In Proceedings of the SIGCHI Conference on Human Factors in Computing Systems (pp. 511-518). Gutwin1998, New York, NY, USA: ACM. http://doi.org/10.1145/274644.274713

Gutwin, C., \& Greenberg, S. (2002). A Descriptive Framework of Workspace Awareness for Real-Time Groupware. Computer Supported Cooperative Work, 11(3), 411-446. Gutwin2002. 
http://doi.org/10.1023/A:1021271517844

Gutwin, C., \& Greenberg, S. (2004). The Importance of Awareness for Team Cognition in Distributed Collaboration. In E. Salas \& S. M. Fiore (Eds.), Team cognition: Understanding the factors that drive processes and performance (pp. 177-201). Gutwin2004.

Hager, P. J., White, C. J., Kurt, S., Cock, J., Meier, B., Seitz, A. R., ... Ross, B. H. (2012). Twenty-First Century Skills and Competencies. In Encyclopedia of the Sciences of Learning (pp. 3353-3356). Boston, MA: Springer US. http://doi.org/10.1007/978-1-4419-1428-6_763

Hainey, T., Connolly, T. M., Boyle, E. A., Wilson, A., \& Razak, A. (2016). A systematic literature review of games-based learning empirical evidence in primary education. Computers \& Education, 102, 202-223. Hainey2016. http://doi.org/10.1016/j.compedu.2016.09.001

Hanus, M. D., \& Fox, J. (2015). Assessing the effects of gamification in the classroom: A longitudinal study on intrinsic motivation, social comparison, satisfaction, effort, and academic performance. Computers \& Education, 80, 152-161. http://doi.org/10.1016/j.compedu.2014.08.019

Harris, C. (2009). Meet the New School Board: Board Games Are Back - And They're Exactly What Your Curriculum Needs. School Library Journal, 55(5), 24-26. Harris2009. Retrieved from http://www.slj.com/2009/05/collection-development/meet-the-new-school-board-board-games-areback-and-theyre-exactly-what-your-curriculum-needs/

Hornecker, E., Marshall, P., Dalton, N. S., \& Rogers, Y. (2008). Collaboration and Interference: Awareness with Mice or Touch Input. In Proceedings of the 2008 ACM Conference on Computer Supported Cooperative Work (pp. 167-176). Hornecker2008, New York, NY, USA: ACM. http://doi.org/10.1145/1460563.1460589

Jadan-Guerrero, J., Jaen, J., Carpio, M. A., \& Guerrero, L. A. (2015). Kiteracy: a kit of tangible objects to strengthen literacy skills in children with down syndrome. In Proceedings of the 14th International Conference on Interaction Design and Children (pp. 315-318). Jadan-Guerrero2015, New York, New York, USA: ACM. http://doi.org/10.1145/2771839.2771905

Janssen, J., Erkens, G., Kanselaar, G., \& Jaspers, J. (2007). Visualization of participation: Does it contribute to successful computer-supported collaborative learning? Computers \& Education, 49(4), 1037-1065. Janssen2007. http://doi.org/10.1016/j.compedu.2006.01.004

Järvelä, S., Häkkinen, P., Arvaja, M., \& Leinonen, P. (2004). Instructional support in CSCL. In What we know about CSCL and implementing it in higher education (pp. 115-139). Kluwer Academic Publishers Norwell.

Johnson, D. W., \& Johnson, R. T. (1989). Cooperation and competition: theory and research. Johnson1989, Interaction Book Co.

Johnson, D. W., \& Johnson, R. T. (1999). Making cooperative learning work. Theory Into Practice, 38(2), 67-73. Johnson1999. http://doi.org/10.1080/00405849909543834

Kapp, K. M. (2012). The Gamification of Learning and Instruction: Game-based Methods and Strategies for Training and Education. John Wiley \& Sons Inc.

Kiili, K., Lainema, T., de Freitas, S., \& Arnab, S. (2014). Flow framework for analyzing the quality of educational games. Entertainment Computing, 5(4), 367-377. http://doi.org/10.1016/j.entcom.2014.08.002

Kocadere, S. A., \& Çağlar, Ş. (2015). The design and implementation of a gamified assessment. Journal of E-Learning and Knowledge Society, 11(3), 85-99.

Krippendorff, K. (2004). Content analysis: An introduction to its methodology (2nd ed.). Krippendorff2004, Thousand Oaks, CA, USA: Sage Publications, Inc.

Kyewski, E., \& Krämer, N. C. (2018). To gamify or not to gamify? An experimental field study of the influence of badges on motivation, activity, and performance in an online learning course. 
Computers \& Education, 118, 25-37. http://doi.org/10.1016/j.compedu.2017.11.006

Laal, M., \& Ghodsi, S. M. (2012). Benefits of collaborative learning. Procedia - Social and Behavioral Sciences, 31, 486-490. Laal2012. http://doi.org/10.1016/j.sbspro.2011.12.091

Laal, M., Laal, M., \& Kermanshahi, Z. K. (2012). 21st Century Learning; Learning in Collaboration. Procedia - Social and Behavioral Sciences, 47, 1696-1701. http://doi.org/10.1016/j.sbspro.2012.06.885

Li, C., Dong, Z., Untch, R. H., \& Chasteen, M. (2013). Engaging Computer Science Students through Gamification in an Online Social Network Based Collaborative Learning Environment. International Journal of Information and Education Technology, 3(1), 72-77. http://doi.org/10.7763/IJIET.2013.V3.237

Li, L.-Y., Chang, C.-W., \& Chen, G.-D. (2009). Researches on using robots in education. In Proceedings of the 4th International Conference on E-Learning and Games (pp. 479-482). Li2009, Springer. http://doi.org/10.1007/978-3-642-03364-3_57

Malinverni, L., \& Burguès, N. P. (2015). The medium matters: the impact of full-body interaction on the socio-affective aspects of collaboration. In Proceedings of the 14th International Conference on Interaction Design and Children (pp. 89-98). Malinverni2015, New York, New York, USA: ACM. http://doi.org/10.1145/2771839.2771849

Marshall, P. (2007). Do tangible interfaces enhance learning? In Proceedings of the 1st international conference on Tangible and embedded interaction (pp. 163-170). Marshall2007, ACM. http://doi.org/10.1145/1226969.1227004

Martin, F. G., Butler, D., \& Gleason, W. M. (2000). Design, story-telling, and robots in Irish primary education. In Proceedings of the 2000 IEEE International Conference on Systems, Man and Cybernetics (Vol. 1, pp. 730-735). IEEE. http://doi.org/10.1109/ICSMC.2000.885082

McNally, M., Goldweber, M., Fagin, B., \& Klassner, F. (2006). Do lego mindstorms robots have a future in CS education? In Proceedings of the 37th SIGCSE technical symposium on Computer science education (pp. 61-62). New York, New York, USA: ACM Press. http://doi.org/10.1145/1121341.1121362

Meerbeek, B., Bingley, P., Rijnen, W., \& van den Hoven, E. (2010). Pipet: a design concept supporting photo sharing. In Proceedings of the 6th Nordic Conference on Human-Computer Interaction Extending Boundaries (pp. 335-342). New York, New York, USA: ACM Press. http://doi.org/10.1145/1868914.1868954

Meier, A., Spada, H., \& Rummel, N. (2007). A rating scheme for assessing the quality of computersupported collaboration processes. International Journal of Computer-Supported Collaborative Learning, 2(1), 63-86. Meier2007. http://doi.org/10.1007/s11412-006-9005-x

Mitgutsch, K., Schirra, S., \& Verrilli, S. (2013). Movers and shakers: designing meaningful conflict in a tablet-based serious game. In CHI'13 Extended Abstracts on Human Factors in Computing Systems (pp. 715-720). Mitgutsch2013, New York, New York, USA: ACM. http://doi.org/10.1145/2468356.2468482

Moccozet, L., Tardy, C., Opprecht, W., \& Leonard, M. (2013). Gamification-based assessment of group work. In 2013 International Conference on Interactive Collaborative Learning (pp. 171-179). IEEE. http://doi.org/10.1109/ICL.2013.6644565

Mubin, O., Stevens, C. J., Shahid, S., Mahmud, A. Al, \& Dong, J.-J. (2013). A Review of the Applicability of Robots in Education. Technology for Education and Learning, 1(1). http://doi.org/10.2316/Journal.209.2013.1.209-0015

Nacher, V., Garcia-Sanjuan, F., \& Jaen, J. (2016a). Evaluating the Usability of a Tangible-Mediated Robot for Kindergarten Children Instruction. In 2016 IEEE 16th International Conference on Advanced Learning Technologies (pp. 130-132). Nacher2016a, IEEE. http://doi.org/10.1109/ICALT.2016.59 
Nacher, V., Garcia-Sanjuan, F., \& Jaen, J. (2016b). Interactive technologies for preschool game-based instruction: Experiences and future challenges. Entertainment Computing, 17, 19-29. Nacher2016. http://doi.org/10.1016/j.entcom.2016.07.001

Nacher, V., Jaen, J., Catala, A., Navarro, E., \& Gonzalez, P. (2014). Improving Pre-Kindergarten Touch Performance. In Proceedings of the 9th ACM International Conference on Interactive Tabletops and Surfaces (pp. 163-166). Nacher2014, New York, USA: ACM. http://doi.org/10.1145/2669485.2669498

Nacher, V., Jaen, J., Navarro, E., Catala, A., \& González, P. (2015). Multi-touch gestures for prekindergarten children. International Journal of Human-Computer Studies, 73, 37-51. Nacher2015. http://doi.org/10.1016/j.ijhcs.2014.08.004

Nah, F. F.-H., Zeng, Q., Telaprolu, V. R., Ayyappa, A. P., \& Eschenbrenner, B. (2014). Gamification of Education: A Review of Literature. In International Conference on HCI in Business (pp. 401-409). Nah2014, Springer. http://doi.org/10.1007/978-3-319-07293-7_39

Nakamura, J., \& Csikszentmihalyi, M. (2008). Flow Theory and Research. In Handbook of Positive Psychology (pp. 195-206). Nakamura2008. http://doi.org/10.1093/oxfordhb/9780195187243.013.0018

Nam, C. W., \& Zellner, R. D. (2011). The relative effects of positive interdependence and group processing on student achievement and attitude in online cooperative learning. Computers \& Education, 56(3), 680-688. Nam2011. http://doi.org/10.1016/j.compedu.2010.10.010

OECD. (2005). The Definition and Selection of Key Competencies. Retrieved from http://www.oecd.org/pisa/35070367.pdf

Panitz, T. (1999). The Motivational Benefits of Cooperative Learning. New Directions for Teaching and Learning, 1999(78), 59-67. Panitz1999. http://doi.org/10.1002/tl.7806

Papert, S. (1980). Mindstorms: Children, Computers, and Powerful Ideas. Hemel Hempstead, Hertfordshire, UK: Harvester Press.

Pindeh, N., Suki, N. M., \& Suki, N. M. (2016). User Acceptance on Mobile Apps as an Effective Medium to Learn Kadazandusun Language. Procedia Economics and Finance, 37, 372-378. Pindeh2016. http://doi.org/10.1016/S2212-5671(16)30139-3

Price, S., Rogers, Y., Scaife, M., Stanton, D., \& Neale, H. (2003). Using “tangibles” to promote novel forms of playful learning. Interacting with Computers, 15(2), 169-185. Price2003. http://doi.org/10.1016/S0953-5438(03)00006-7

Rädle, R., Jetter, H.-C., Marquardt, N., Reiterer, H., \& Rogers, Y. (2014). HuddleLamp: Spatially-aware mobile displays for ad-hoc around-the-table collaboration. In Proceedings of the 9 th ACM International Conference on Interactive Tabletops and Surfaces (pp. 45-54). Radle2014, New York, USA: ACM. http://doi.org/10.1145/2669485.2669500

Rathunde, K. (2003). A Comparison of Montessori and Traditional Middle Schools: Motivation, Quality of Experience, and Social Context. The NAMTA Journal, 28(3), 12-52. Rathunde2003.

Read, J. C. (2008). Validating the Fun Toolkit: an instrument for measuring children's opinions of technology. Cognition, Technology \& Work, 10(2), 119-128. Read2008. http://doi.org/10.1007/s10111-007-0069-9

Read, J. C., \& MacFarlane, S. (2006). Using the fun toolkit and other survey methods to gather opinions in child computer interaction. In Proceedings of the 2006 conference on Interaction design and children (pp. 81-88). Read2006, New York, New York, USA: ACM. http://doi.org/10.1145/1139073.1139096

Rick, J. (2012). Proportion: a tablet app for collaborative learning. In Proceedings of the 11th International Conference on Interaction Design and Children (pp. 316-319). Rick2012, New York, New York, USA: ACM. http://doi.org/10.1145/2307096.2307155 
Rick, J., Marshall, P., \& Yuill, N. (2011). Beyond One-size-fits-all: How Interactive Tabletops Support Collaborative Learning. In Proceedings of the 10th International Conference on Interaction Design and Children (pp. 109-117). Rick2011, New York, NY, USA: ACM. http://doi.org/10.1145/1999030.1999043

Robertson, M. (2010). Can’t Play, Won’t Play. Retrieved January 1, 2018, from https://kotaku.com/5686393/cant-play-wont-play

Romero, M., Usart, M., Ott, M., Earp, J., de Freitas, S., \& Arnab, S. (2012). Learning through playing for or against each other? Promoting collaborative learning in digital game based learning. In ECIS 2012 Proceedings. Retrieved from https://aisel.aisnet.org/ecis2012/93

Şahin, Y. L., Karadağ, N., Bozkurt, A., Doğan, E., Kılınç, H., Uğur, S., .. Güler, C. (2017). The Use of Gamification in Distance Education: A Web-Based Gamified Quiz Application. Turkish Online Journal of Qualitative Inquiry, 8(4), 372-395.

Schneider, B., Jermann, P., Zufferey, G., \& Dillenbourg, P. (2011). Benefits of a Tangible Interface for Collaborative Learning and Interaction. IEEE Transactions on Learning Technologies, 4(3), 222 232. Schneider2011. http://doi.org/10.1109/TLT.2010.36

Seitinger, S. (2006). An ecological approach to children's playground props. In Proceedings of the 2006 conference on Interaction Design and Children (pp. 117-120). Seitinger2006, New York, New York, USA: ACM. http://doi.org/10.1145/1139073.1139103

Shernoff, D. J., Csikszentmihalyi, M., Shneider, B., \& Shernoff, E. S. (2003). Student engagement in high school classrooms from the perspective of flow theory. School Psychology Quarterly, 18(2), 158176. Shernoff2003. http://doi.org/10.1521/scpq.18.2.158.21860

Shneiderman, B., Plaisant, C., Cohen, M., \& Jacobs, S. (2009). Designing the User Interface: Strategies for Effective Human-Computer Interaction. Shneiderman2009, Boston, MA: Addison-Wesley Longman Publishing Co., Inc.

Simões, J., Redondo, R. D., \& Vilas, A. F. (2013). A social gamification framework for a K-6 learning platform. Computers in Human Behavior, 29(2), 345-353. http://doi.org/10.1016/j.chb.2012.06.007

Slavin, R. E. (1996). Research on Cooperative Learning and Achievement: What We Know, What We Need to Know. Contemporary Educational Psychology, 21(1), 43-69. Slavin1996. http://doi.org/10.1006/ceps.1996.0004

Soute, I., Markopoulos, P., \& Magielse, R. (2010). Head Up Games: combining the best of both worlds by merging traditional and digital play. Personal and Ubiquitous Computing, 14(5), 435-444. Soute2010. http://doi.org/10.1007/s00779-009-0265-0

Staiano, A. E., \& Calvert, S. L. (2011). Exergames for Physical Education Courses: Physical, Social, and Cognitive Benefits. Child Development Perspectives, 5(2), 93-98. http://doi.org/10.1111/j.17508606.2011.00162.x

Stanton, D., Pridmore, T., Bayon, V., Neale, H., Ghali, A., Benford, S., .. Wilson, J. (2001). Classroom collaboration in the design of tangible interfaces for storytelling. In Proceedings of the SIGCHI conference on Human factors in computing systems (pp. 482-489). Stanton2001, New York, New York, USA: ACM. http://doi.org/10.1145/365024.365322

Stiggins, R., \& Chappuis, J. (2001). An Introduction to Student-Involved Assessment FOR Learning. Pearson Education.

Strawhacker, A., \& Bers, M. U. (2014). "I want my robot to look for food”: Comparing Kindergartner's programming comprehension using tangible, graphic, and hybrid user interfaces. International Journal of Technology and Design Education. Strawhacker2014. http://doi.org/10.1007/s10798014-9287-7

Sun, H. (2012). Exergaming Impact on Physical Activity and Interest in Elementary School Children. Research Quarterly for Exercise and Sport, 83(2), 212-220. 
http://doi.org/10.1080/02701367.2012.10599852

Szewkis, E., Nussbaum, M., Rosen, T., Abalos, J., Denardin, F., Caballero, D., ... Alcoholado, C. (2011). Collaboration within large groups in the classroom. International Journal of Computer-Supported Collaborative Learning, 6(4), 561-575. Szewkis2011a. http://doi.org/10.1007/s11412-011-9123-y

Tan, J. L., Goh, D. H.-L., Ang, R. P., \& Huan, V. S. (2016). Learning efficacy and user acceptance of a game-based social skills learning environment. International Journal of Child-Computer Interaction, 9-10, 1-19. Tan2016. http://doi.org/10.1016/j.ijcci.2016.09.001

Tanaka, Y., Uwano, H., Ichinose, T., \& Takehara, S. (2016). Effects of Gamified Quiz to Student's Motivation and Score. In 2016 8th International Conference on Games and Virtual Worlds for Serious Applications (pp. 1-4). IEEE. http://doi.org/10.1109/VS-GAMES.2016.7590345

Tomporowski, P. D., Lambourne, K., \& Okumura, M. S. (2011). Physical activity interventions and children's mental function: An introduction and overview. Preventive Medicine, 52(1), S3-S9. Tomporowski2011. http://doi.org/10.1016/j.ypmed.2011.01.028

Tsihouridis, C., Vavougios, D., \& Ioannidis, G. S. (2017). Assessing the Learning Process Playing with Kahoot - A Study with Upper Secondary School Pupils Learning Electrical Circuits. In 20th International Conference on Interactive Collaborative Learning (pp. 602-612). Springer. http://doi.org/10.1007/978-3-319-73210-7_70

Tuddenham, P., Kirk, D., \& Izadi, S. (2010). Graspables revisited: multi-touch vs. tangible input for tabletop displays in acquisition and manipulation tasks. In Proceedings of the 28th international conference on Human factors in computing systems (pp. 2223-2232). Tuddenham2010, New York, New York, USA: ACM. http://doi.org/10.1145/1753326.1753662

Wagner, T. (2008). The Global Achievement Gap: Why Even Our Best Schools Don't Teach the New Survival Skills Our Children Need - and What We Can Do About It.

Werbach, K., \& Hunter, D. (2012). For The Win: How Game Thinking Can Revolutionize Your Business. Werbach2012, Wharton Digital Press.

Westergaard, J. (2009). Effective Group Work with Young People. Westergaard2009, Berkshire, UK: Open University Press.

Wichadee, S., \& Pattanapichet, F. (2018). Enhancement of Performance and Motivation through Application of Digital Games in an English Language Class. Teaching English with Technology, 18(1), 77-92.

Wise, A., Antle, A., Warren, J. L., May, A., Fan, M., \& Macaranas, A. (2015). What Kind of World Do You Want to Live In?: Positive Interdependence and Collaborative Processes in the Tangible Tabletop Land-Use Planning Game Youtopia Collaborative Learning with Interactive Tabletops. In Proceedings of the 11th International Conference on Computer Supported Learning (pp. 236-243).

Xie, L., Antle, A. N., \& Motamedi, N. (2008). Are tangibles more fun?: comparing children's enjoyment and engagement using physical, graphical and tangible user interfaces. In Proceedings of the $2 n d$ international conference on Tangible and embedded interaction (pp. 191-198). Xie2008, New York, New York, USA: ACM. http://doi.org/10.1145/1347390.1347433

Zacharia, Z. C., \& Olympiou, G. (2011). Physical versus virtual manipulative experimentation in physics learning. Learning and Instruction, 21(3), 317-331. Zacharia2011. http://doi.org/10.1016/j.learninstruc.2010.03.001

Zagal, J. P., Rick, J., \& Hsi, I. (2006). Collaborative games: Lessons learned from board games. Simulation \& Gaming, 37(1), 24-40. Zagal2006. http://doi.org/10.1177/1046878105282279 